\title{
NEXAFS spectroscopy of ionic liquids: experiments versus calculations
}

Richard M. Fogarty, ${ }^{1}$ Richard P. Matthews, ${ }^{1}$ Matthew T. Clough, ${ }^{1}$ Claire R. Ashworth, ${ }^{1}$ Agnieszka Brandt, ${ }^{2}$ Paul J. Corbett, ${ }^{2}$ Robert G. Palgrave,${ }^{3}$ Richard A. Bourne, ${ }^{4,5}$ Thomas W. Chamberlain, ${ }^{5}$ Tom Vander Hoogerstraete, ${ }^{6}$ Paul B. J. Thompson, ${ }^{7}$ Patricia A. Hunt, ${ }^{1}$ Nicholas A. Besley, ${ }^{8}$ Kevin R. J. Lovelock. ${ }^{* 9}$

${ }^{1}$ Department of Chemistry, Imperial College London, UK

${ }^{2}$ Department of Chemical Engineering, Imperial College London, UK

${ }^{3}$ Department of Chemistry, University College London, UK

${ }^{4}$ School of Chemical and Process Engineering, University of Leeds, UK

${ }^{5}$ Institute of Process Research and Development, School of Chemistry, University of Leeds, UK ${ }^{6}$ Department of Chemistry, KU Leuven, Belgium

${ }^{7}$ XMaS, UK CRG, ESRF, France, and Department of Physics, University of Liverpool, UK

${ }^{8}$ School of Chemistry, University of Nottingham, UK

${ }^{9}$ Department of Chemistry, University of Reading, UK

Contact E-mail: k.r.j.lovelock@reading.ac.uk; nick.besley@nottingham.ac.uk

\begin{abstract}
Experimental near edge X-ray absorption fine structure (NEXAFS) spectra are reported for 12 ionic liquids (ILs) encompassing a range of chemical structures for both the sulfur $1 \mathrm{~s}$ and nitrogen $1 \mathrm{~s}$ edges and compared with time-dependent density functional theory (TD-DFT) calculations. The energy scales for the experimental data were carefully calibrated against literature data. Gas phase calculations were performed on lone ions, ion pairs and ion pair dimers, with a wide range of ion pair conformers considered. For the first time, it is demonstrated that TD-DFT is a suitable method for simulating NEXAFS spectra of ILs, although the number of ions included in the calculations and their conformations are important considerations. For most of the ILs studied, calculations on lone ions in the gas phase were sufficient to successfully reproduce the experimental NEXAFS spectra. However, for certain ILs - for example, those containing a protic ammonium cation calculations on ion pairs were required to obtain a good agreement with experimental spectra. Furthermore, significant conformational dependence was observed for the protic ammonium ILs, providing insight into the predominant liquid phase cation-anion interactions. Among the 12 investigated ILs, we find that four have an excited state that is delocalised across both the cation and the anion, which has implications for any process that depends upon the excited state, for example, radiolysis. Considering the collective experimental and theoretical data, we recommend that ion pairs should be the minimum number of ions used for the calculations of NEXAFS spectra of ILs.
\end{abstract}

\section{Introduction}

lonic liquids (ILs) are liquids composed entirely of mobile ions. There is an essentially inexhaustible number of potential ILs and, considering the broad range of physicochemical properties attainable by combining different cations and anions, the overarching characteristics of ILs are difficult to pinpoint. IL-based systems have the potential to affect a wide array of energy technologies: ${ }^{1}$ electrochemical applications (such as supercapacitors, fuel cells, photoelectrochemical cells and batteries), ${ }^{2}$ nuclear fuel processing, ${ }^{3}$ deconstruction of lignocellulosic biomass, ${ }^{4}$ and gas separation/capture/storage ${ }^{5}$. Knowledge of liquid phase electronic structure, and therefore reactivity, is crucial in order to understand the chemical processes that underpin these applications. In particular, the excited states of IL-based systems contribute significantly to many areas, including chemical reactivity (e.g. reduction reactions), ${ }^{6-8}$ the electrochemical window, ${ }^{9-14}$ and radiolysis ${ }^{15-21}$. However, IL excited states have been studied far less than IL ground states, ${ }^{22}$ due to the greater experimental and computational challenges. 
Near edge X-ray absorption fine structure (NEXAFS) spectroscopy is an element- and sitespecific technique that can be applied to all elements (other than $\mathrm{H}$ and $\mathrm{He}$ ) and is used to investigate the electronic properties of materials, in particular the excited states. ${ }^{23-25}$ The specificity of NEXAFS spectroscopy renders it an attractive technique for investigating elements that are essentially silent by NMR spectroscopy, for example, sulfur. ${ }^{26-29}$ NEXAFS spectroscopy involves the study of the absorption of an X-ray photon by the element of interest, leading to promotion of an electron from a core orbital to a previously unoccupied molecular orbital (UMO). Absorption is generally indirectly monitored by measurement of either the fluorescence yield (FY) or the electron yield (EY), e.g. partial EY (PEY). ${ }^{23} \mathrm{FY}$ and PEY can provide subtly different measures of absorption, as the physical processes following core-hole creation are different. $^{30,} 31$ EY detection requires ultrahigh vacuum (UHV) conditions for the detector and therefore, with the notable exception of rare specialist apparatus, ${ }^{25,30,31}$ excludes the study of molecular liquids using soft X-rays. However, ILs are sufficiently non-volatile that standard soft X-ray apparatus can be used to study the liquid phase at room temperature. ${ }^{22,32}$

To date, experimental NEXAFS spectroscopy of ILs has focused almost exclusively on aprotic dialkylimidazolium-based ILs $\left(\left[\mathrm{C}_{n} \mathrm{C}_{1} \mathrm{Im}\right]^{+}\right),{ }^{33-42}$ primarily at the $\mathrm{N} 1 \mathrm{~s}$ edge ${ }^{33-40}$. For ILs, other edges that have been studied in the soft $\mathrm{X}$-ray regime include $\mathrm{Cl} 2 \mathrm{p},{ }^{37} \mathrm{O} 1 \mathrm{~s},{ }^{37} \mathrm{~F} 1 \mathrm{~s}^{33,37}$ and $\mathrm{C} 1 \mathrm{~s},{ }^{38}$ and in the tender $\mathrm{X}$-ray regime $(1.5 \mathrm{keV}<h v<5 \mathrm{keV}) \mathrm{S} 1 \mathrm{~s} .{ }^{37,43}$ ILs studied at the $\mathrm{N} 1 \mathrm{~s}$ edge have mainly contained nitrogen in the cation and not the anion $\left(\left[\mathrm{C}_{4} \mathrm{C}_{1} \mathrm{Im}\right] \mathrm{Cl}\right.$, $\left[\mathrm{C}_{4} \mathrm{C}_{1} \mathrm{Im}\right] \mathrm{Br}, \quad\left[\mathrm{C}_{4} \mathrm{C}_{1} \mathrm{Im}\right] \mathrm{l}, \quad\left[\mathrm{C}_{4} \mathrm{C}_{1} \mathrm{Im}\right]\left[\mathrm{BF}_{4}\right]$ and $\left.\left[\mathrm{C}_{4} \mathrm{C}_{1} \mathrm{Im}\right]\left[\mathrm{PF}_{6}\right]\right)$. One exception to this is $\left[\mathrm{C}_{4} \mathrm{C}_{1}\right.$ Im] $\left[\mathrm{NTf}_{2}\right]$, where $\left[\mathrm{NTf}_{2}\right]^{-}$is the bis[(trifluoromethane)sulfonyl]imide ion. A peak arising from an N 1s $\rightarrow 2 \mathrm{p} \pi^{*}$ transition was identified at $h v \sim 401.9 \mathrm{eV}$ for all six of the $\left[\mathrm{C}_{n} \mathrm{C}_{1} \mathrm{Im}\right]^{+}-$ based ILs listed above; $;^{33,35-40}$ as two of these samples were solids, the NEXAFS data is of limited value for understanding the properties of the liquid state. For $\left[\mathrm{C}_{4} \mathrm{C}_{1} I \mathrm{Im}\right]\left[\mathrm{NTf}_{2}\right]$, no clear peak arising from the $\left[\mathrm{NTf}_{2}\right]^{-}$anion was identified. ${ }^{37-39}$ Protic samples that are structurally very similar to the dialkylimidazolium-based ILs listed above have also been studied using NEXAFS spectroscopy, although both $\left[\mathrm{C}_{1} \mathrm{C}_{0} \mathrm{Im}\right] \mathrm{Cl}$ and $\left[\mathrm{C}_{1} \mathrm{C}_{0} \mathrm{Im}\right]\left[\mathrm{NTf}_{2}\right]$ (where $\mathrm{C}_{0}$ represents a proton attached to a nitrogen atom to give $\mathrm{N}-\mathrm{H}$ ) are solids. ${ }^{37}$

Calculated NEXAFS spectra can play an important part in the interpretation of experimental spectra and can provide significantly greater insight than that available from experiments alone. When simulating NEXAFS spectra for ILs, at least two important questions must be addressed. The first relates to the choice of the computational method: what is the most appropriate method to use? The second concerns the structure: what is the optimum model system to use, e.g. an ion pair, and what is the role of conformation? The answers to these questions will be dependent, at least in part, on the level of accuracy that can be achieved at a practical computational cost.

NEXAFS spectra are commonly calculated using the transition-potential density functional theory (TP-DFT $)^{44}$ method. In this approach, the orbital binding energy is calculated as the derivative of the total energy with respect to the orbital occupation number. To account for orbital relaxation, the energy is approximated by the derivative at the point corresponding to an occupation of one half. Formally, this corresponds to a core orbital with half an electron removed, capturing a balance between the final and initial states. A potentially more accurate approach is time-dependent density functional theory (TD-DFT), ${ }^{45}$ a wellestablished method for studying the excited states of molecular systems. ${ }^{25}$ However, TDDFT with standard exchange-correlation functionals significantly underestimates the transition energies of core excitations. This failing has been addressed through the introduction of short-range corrected exchange-correlation functionals, which provide accurate core-excitation energies. ${ }^{46}$

Any model system used to simulate ILs must capture the bulk IL environment to a sufficient 
degree. For ILs, cations and anions experience different solvation environments in the liquid phase ${ }^{47}$ which may be important for calculated NEXAFS spectra of ILs. For the calculation of IL excited states, the number of ions used in calculations (i.e. the system size) has been shown to be important, ${ }^{19}$ because the excited state may be delocalised and spread across multiple ions. Therefore, large model systems may be needed to successfully calculate NEXAFS spectra of ILs. However, ground state ab initio calculations on ILs have primarily considered ion pairs (one cation and one anion) in the gas phase,${ }^{48-50}$ which do not always reflect the bulk IL properties. ${ }^{51}$ Recently, calculations on more complex systems -such as ion pair dimers (two cations and two anions) in the gas phase and ions in a polarisable continuum - have been reported. ${ }^{51-56}$ It has been shown that calculations for either lone ions or ion pairs in an IL-parameterised solvent continuum give excellent agreement with experimental valence band spectra. ${ }^{51}$ These calculations demonstrate that, for the occupied orbitals at least, calculations on small model systems (i.e. those with a small number of ions) can describe the liquid phase behaviour to an acceptable level. For small model systems the conformation is also expected to be important for many properties. A thorough conformational analysis is particularly relevant for ILs since there are often multiple low energy conformers of the individual ions and ion pairs that can contribute to the property being studied. ${ }^{48,49}$ Calculations on ion pair dimers are demanding, both in terms of user time cost (surveying a wide range of possible conformer structures) and computational cost (optimisation of conformers and calculating NEXAFS spectra).

To date, only two studies have reported calculated NEXAFS spectra (for three ILs in total) using TP-DFT; to the best of our knowledge no studies have used TD-DFT to calculate NEXAFS spectra for ILs. Both of the TP-DFT studies involved calculations on relatively small model systems in the gas phase, with no ion pair conformational dependence considered. This highlights the limited literature on the comparison of experimental and calculated NEXAFS spectra for ILs (although plenty of NEXAFS calculations have been reported for molecular liquids such as water ${ }^{25}$ ). The accuracy of the calculated NEXAFS spectra was assessed by the ability of the calculations to reproduce both the experimental spectral shape and experimental edge energies. Ehlert et al. used TP-DFT to study $\left[\mathrm{C}_{1} \mathrm{C}_{1} \mathrm{Im}\right]\left[\mathrm{NTf} \mathrm{f}_{2}\right]$ and $\left[\mathrm{C}_{4} \mathrm{C}_{1} \mathrm{Im}\right] \mathrm{l}$; for each IL only one ion pair conformer (chosen from solid state crystal structures) in the gas phase was considered. ${ }^{38}$ An energy shift of $-1.6 \mathrm{eV}$ was applied to the calculated $\mathrm{N}$ 1s NEXAFS spectrum for $\left[\mathrm{C}_{1} \mathrm{C}_{1} \mid \mathrm{m}\right]\left[\mathrm{NTf} \mathrm{f}_{2}\right]$ to achieve a good visual match with the experimental $\mathrm{N}$ 1s NEXAFS spectrum for $\left[\mathrm{C}_{4} \mathrm{C}_{1} \mathrm{Im}\right]\left[\mathrm{NTf}_{2}\right]$. The lowest energy peak in the calculated $\left[\mathrm{C}_{1} \mathrm{C}_{1} I \mathrm{~m}\right]\left[\mathrm{NTf}_{2}\right] \mathrm{N}$ 1s spectrum had significant contributions from both $\left[\mathrm{NTf}_{2}\right]^{-}$and $\left[\mathrm{C}_{1} \mathrm{C}_{1} \mathrm{~lm}\right]^{+}$. This finding highlights why no clear peak attributable to the $\left[\mathrm{NTf}_{2}\right]^{-}$ anion could be identified in experimental $N$ 1s NEXAFS spectra for $\left[\mathrm{C}_{n} \mathrm{C}_{1} \mathrm{Im}_{\mathrm{m}}\right]\left[\mathrm{NTf} \mathrm{f}_{2}\right]$. $^{37-39}$ Horikawa et al. used TP-DFT on isolated (i.e. lone) $\left[\mathrm{C}_{2} \mathrm{C}_{1} \mathrm{Im}\right]^{+}$and $\left[\mathrm{NTf}_{2}\right]^{-}$ions. ${ }^{39}$ For calculations on lone $\left[\mathrm{NTf}_{2}\right]^{-}$and lone $\left[\mathrm{C}_{2} \mathrm{C}_{1} \mathrm{Im}\right]^{+}$, similar results to Ehlert et al ${ }^{38}$ were found for the $\mathrm{N} 1 \mathrm{~s}$ edge. $\mathrm{A}+1.0 \mathrm{eV}$ energy shift was needed for the calculated NEXAFS spectrum for lone $\left[\mathrm{NTf}_{2}\right]^{-}$to obtain the best match to the $\left[\mathrm{C}_{2} \mathrm{C}_{1} \mathrm{Im}\right]\left[\mathrm{NTf}_{2}\right]$ experimental $\mathrm{N}$ 1s spectrum; no shift was reported for the lone $\left[\mathrm{C}_{2} \mathrm{C}_{1} \mathrm{~lm}\right]^{+}$calculations. Overall, the lack of a clearly identifiable experimental peak associated with the $\left[\mathrm{NTf}_{2}\right]^{-}$anion means that $\left[\mathrm{C}_{n} \mathrm{C}_{1} \mathrm{Im}\right]\left[\mathrm{NTf} \mathrm{f}_{2}\right]$ ILs are not ideal candidates for comparing calculated and experimental NEXAFS spectra.

In this paper we report a detailed study on the NEXAFS spectroscopy of ILs; we provide new experimental NEXAFS spectra, assess the accuracy of TD-DFT calculations of NEXAFS spectra and offer new insights into the excited states. We have measured seven different experimental NEXAFS spectra at the $S$ 1s edge and seven at the $N$ 1s edge for a total of 12 structurally related ILs, with both the $S 1 \mathrm{~s}$ and $\mathrm{N}$ 1s edges studied for $\left[\mathrm{C}_{4} \mathrm{C}_{1} \mathrm{Im}\right][\mathrm{SCN}]$ and $\left[\mathrm{C}_{8} \mathrm{C}_{1} \mathrm{Im}\right]\left[\mathrm{NTf}_{2}\right]$ (Table 1). These ILs were chosen for their wide range of both sulfur and nitrogen chemical environments.

TD-DFT NEXAFS spectra have been calculated for both the $S$ 1s and $N$ 1s edges for multiple system sizes: Ione ions, ion pairs and ion pair dimers. For all 12 ILs, calculations 
were performed for both lone ions and at least three ion pair conformations. We restricted our ion pair dimer calculations to a smaller number of ILs and edges: $S$ 1s TD-DFT calculations for $\left[\mathrm{C}_{4} \mathrm{C}_{1} \mathrm{Im}\right]\left[\mathrm{MeSO}_{4}\right]$ ion pair dimers and $\mathrm{N}$ 1s TD-DFT calculations for $\left[\mathrm{C}_{2} \mathrm{C}_{1} \mathrm{Im}\right] \mathrm{Cl}$ ion pair dimers. The nomenclature used for labelling ion pair and ion pair dimer calculations is given in the Supplementary Information. ILs that give rise to peaks from both the cation and the anion in the same NEXAFS spectrum, e.g. $\left[\mathrm{C}_{4} \mathrm{C}_{1} \operatorname{lm}\right]\left[\mathrm{C}(\mathrm{CN})_{3}\right]$ for the $\mathrm{N} 1 \mathrm{~s}$ edge, are particularly important; such ILs ensure that the TD-DFT calculations capture the liquid phase solvation environment for the both the cation and the anion, providing an excellent test of our chosen TD-DFT calculations. Using our combination of experiments and calculations, excited states of ILs are investigated, with particular focus on ILs with either a protic cation or a $\mathrm{Cl}$ - anion, enabling us to draw new conclusions on the excited states of ILs. 


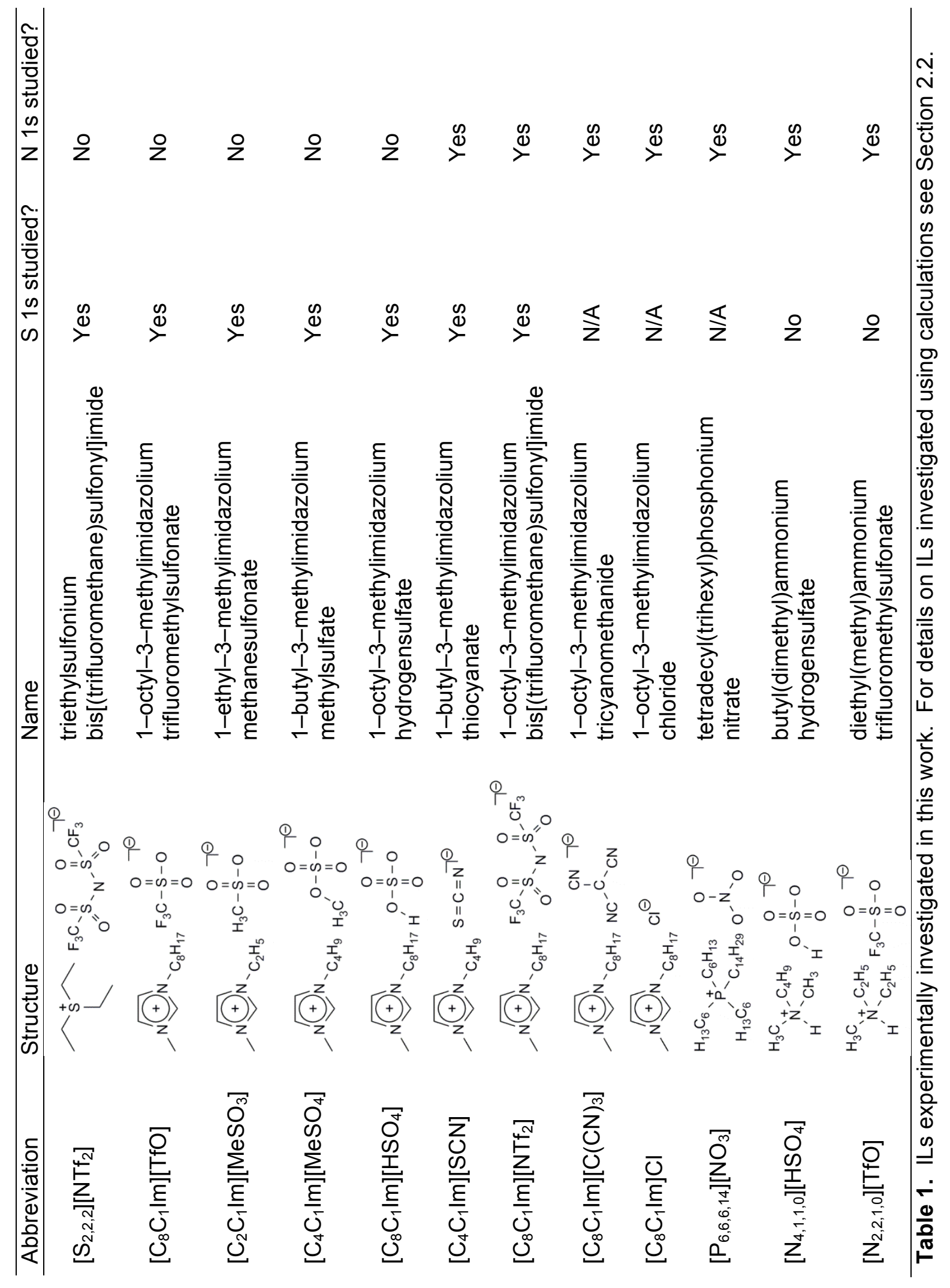




\section{Experimental Section}

\subsection{Ionic liquids synthesis}

Select ILs were purchased from Sigma-Aldrich ([S $\left.\mathrm{S}_{2,2,2}\right]\left[\mathrm{NTf}_{2}\right], \quad\left[\mathrm{C}_{8} \mathrm{C}_{1} \mathrm{Im}\right][\mathrm{TfO}]$ and $\left.\left[\mathrm{C}_{4} \mathrm{C}_{1} \mathrm{Im}\right][\mathrm{SCN}]\right)$ and lolitec $\left(\left[\mathrm{C}_{8} \mathrm{C}_{1} \mathrm{Im}\right]\left[\mathrm{C}(\mathrm{CN})_{3}\right]\right.$ and $\left.\left[\mathrm{N}_{2,2,1,0}\right][\mathrm{TfO}]\right)$. The other investigated ILs were prepared in our laboratories via established synthetic methods $\left(\left[\mathrm{N}_{4,1,1,0}\right]\left[\mathrm{HSO}_{4}\right],{ }^{57}\right.$ $\left[\mathrm{P}_{6,6,6,14]}\right]\left[\mathrm{NO}_{3}\right],{ }^{58}\left[\mathrm{C}_{2} \mathrm{C}_{1} \mathrm{Im}\right]\left[\mathrm{MeSO}_{3}\right],{ }^{59}\left[\mathrm{C}_{4} \mathrm{C}_{1} \mathrm{Im}\right]\left[\mathrm{MeSO}_{4}\right],{ }^{60}\left[\mathrm{C}_{n} \mathrm{C}_{1} \mathrm{Im}\right]\left[\mathrm{NTf}_{2}\right]\left(n=2,4,8\right.$ and 12), ${ }^{60}$ and $\left.\left[\mathrm{C}_{8} \mathrm{C}_{1} \mathrm{Im}\right] \mathrm{Cl}^{60}\right)$ or via a modified procedure $\left(\left[\mathrm{C}_{8} \mathrm{C}_{1} \mathrm{Im}\right]\left[\mathrm{HSO}_{4}\right]\right.$, see below). The purities of all IL samples synthesised in our laboratories were assessed using ${ }^{1} \mathrm{H}$ NMR and ${ }^{13} \mathrm{C}$ NMR spectroscopy. The low chamber pressures for both $S$ 1s and N 1s NEXAFS spectroscopy experiments (see Section 2.2 below) ensures that all volatile impurities, most importantly water, were highly likely to have been removed prior to data collection, leading to high purity samples. ${ }^{61}$ Sample purity was also confirmed by X-ray photoelectron survey spectra. ${ }^{62,63}$

Synthesis of 1-octyl-3-methylimidazolium hydrogen sulfate, $\left[\mathrm{C}_{8} \mathrm{C}_{1} \mathrm{Im}\right]\left[\mathrm{HSO}_{4}\right]$

A round-bottomed flask was fitted with two bubblers (charged with $1 \mathrm{M}$ aqueous sodium hydroxide) and a dropping funnel. Sulfuric acid $98 \%(22.18 \mathrm{~g}, 0.23 \mathrm{~mol})$ was added dropwise to a cold mixture of 1-octyl-3-methylimidazolium chloride $(50.00 \mathrm{~g}, 0.22 \mathrm{~mol})$ and water $(50 \mathrm{ml})$ over a period of one hour. The water was removed via rotary evaporation and the remaining liquid was dried in vacuo (24 hours) to yield 1-octyl-3-methylimidazolium hydrogen sulfate $(62.48 \mathrm{~g}, 97.1 \%)$ as a colourless viscous liquid. ${ }^{1} \mathrm{H}$ NMR spectroscopy $\left(400 \mathrm{MHz}, \mathrm{DMSO}-\mathrm{d}_{6}\right): \delta 11.25(\mathrm{~s}, 2 \mathrm{H}), 8.56(\mathrm{~s}, 1 \mathrm{H}), 7.12(\mathrm{~d}, J=18.6 \mathrm{~Hz}, 2 \mathrm{H}), 3.38(\mathrm{~s}, 3 \mathrm{H})$, $1.26(\mathrm{~s}, 2 \mathrm{H}), 0.66(\mathrm{~s}, 5 \mathrm{H}), 0.56(\mathrm{~s}, 6 \mathrm{H}), 0.16(\mathrm{~s}, 3 \mathrm{H}) .{ }^{13} \mathrm{C}$ NMR spectroscopy $(101 \mathrm{MHz}$, DMSO- $\mathrm{d}_{6}$ ): $\delta 136.24,135.19,123.22,122.90,121.88,119.27,48.87,40.39,40.18,39.97$, $39.76,39.55,35.58,35.37,31.18,29.56,29.45,28.55,28.44,25.55,21.97,13.29 . \mathrm{m} / \mathrm{z}$ (LSIMS $\left.{ }^{+}\right): 195(100 \%)\left[\mathrm{C}_{8} \mathrm{C}_{1} \mathrm{Im}\right]^{+} . \mathrm{m} / \mathrm{z}\left(\mathrm{LSIMS}^{-}\right): 97(100 \%)\left[\mathrm{HSO}_{4}\right]^{-}$. Calc. for $\mathrm{C}_{12} \mathrm{H}_{24} \mathrm{~N}_{2} \mathrm{O}_{4} \mathrm{~S}$ : C, 49.29; H, 8.27; N, 9.58\%. Measured: C, 49.14; H, 8.34; N, 9.57\%.

\subsection{NEXAFS spectroscopy}

$S$ 1s NEXAFS spectra were collected on beamline BM28 of the European Synchrotron Radiation Facility (ESRF) using a $\mathrm{Si}(111)$ double crystal monochromator with an electron beam energy of $6 \mathrm{GeV}$ and current of $200 \mathrm{~mA}$. Spectra were collected in fluorescence mode. $^{43} \mathrm{~S} 1 \mathrm{~s}$ and $\mathrm{N}$ 1s edge white line energies, $E_{\mathrm{WL}}(\exp )$, were obtained by fitting a smoothing spline to the measured spectra and taking the first maximum of the fitted spectra. The chamber pressure was $\sim 10^{-7}$ mbar during measurements. $N$ 1s NEXAFS spectra were collected at MAX-lab (beamline 1311). A drop of IL was deposited onto a molybdenum sample plate. The sample was placed in a load lock chamber and pumped down slowly to $10^{-6} \mathrm{mbar}$ before being transferred to an analysis chamber $\left(10^{-9} \mathrm{mbar}\right)$. Etching was carried out with a $500 \mathrm{eV} \mathrm{Ar}^{+}$ion gun. The chamber pressure was $\sim 5 \times 10^{-10}$ mbar during measurements. For both the $S 1 \mathrm{~s}$ and $\mathrm{N}$ 1s results, no energy calibration of the data after recording was required (the data acquired in these investigations matches within experimental error with examples from the literature, as discussed in further detail in Section 3.1 and in the Supplementary Information).

All structures were optimised in the gas phase at the B3LYP-D3BJ/6-311+G(d,p) level of theory ${ }^{64-68}$ as implemented in the Gaussian 09 suite of programs. Dispersion was accounted for by using Grimme's D3 dispersion correction combined with Becke-Johnson damping. ${ }^{69}$ Structures were optimised under no symmetry constraints and confirmed as minima by frequency analysis. Numerical integration was carried out using a pruned grid of 99 radial shells and 590 angular points per shell. The self-consistent field convergence criteria were set to $10^{-9}$ au for the density matrix and $10^{-7}$ au for the energy matrix. For $\left[\mathrm{C}_{n} \mathrm{C}_{1} \mathrm{Im}\right][\mathrm{A}] \mathrm{ILs}$ the $\left[\mathrm{C}_{4} \mathrm{C}_{1} \mathrm{Im}\right]^{+}$cation was used in calculations to save computational time (e.g. the $\left[\mathrm{C}_{8} \mathrm{C}_{1} \mathrm{Im}\right]\left[\mathrm{HSO}_{4}\right]$ NEXAFS spectra were calculated using $\left[\mathrm{C}_{4} \mathrm{C}_{1} \mathrm{Im}\right]\left[\mathrm{HSO}_{4}\right]$ ion pairs), and for 
$\left[\mathrm{P}_{6,6,6,14}\right]\left[\mathrm{NO}_{3}\right]$ the $\left[\mathrm{P}_{2,2,2,4}\right]^{+}$cation was used. For all ILs a range of conformers have been examined, details of relevant structures and energies can be found in the ESI.

NEXAFS spectra were calculated using TD-DFT within the Tamm-Dancoff approximation. ${ }^{70}$ The calculations were performed using a restricted single excitation subspace that only included excitations from the relevant core orbital(s). A short-range corrected exchangecorrelation functional, denoted SRC1, was used with parameters of $\mathrm{C}_{\mathrm{SHF}}=0.50, \mathrm{C}_{\mathrm{LHF}}=0.17$, $\mu_{\mathrm{SR}}=0.56 \mathrm{a}_{\mathrm{o}}{ }^{-1}$ and $\mu_{\mathrm{LR}}=2.45 \mathrm{a}_{0}{ }^{-1}$ for the nitrogen $1 \mathrm{~s}$ edge spectra and $\mathrm{C}_{\mathrm{SHF}}=0.87, \mathrm{C}_{\mathrm{LHF}}=$ $0.25, \mu_{\mathrm{SR}}=2.20 \mathrm{a}_{\mathrm{o}}{ }^{-1}$ and $\mu_{\mathrm{LR}}=1.80 \mathrm{a}_{\mathrm{o}}{ }^{-1}$ for the sulfur $1 \mathrm{~s}$ edge spectra ${ }^{45,46}$ in conjunction with the $6-311(2+, 2+) G(d, p)$ basis set. These short-range corrected functionals have been designed to predict core-excitation energies accurately and have been applied to study the NEXAFS spectra of a range of systems. ${ }^{71-73}$ The computational cost of the calculations was reduced by using a modified two-electron screening procedure with a reduced quality numerical integration grid in the TD-DFT calculations. ${ }^{74,75}$ The TD-DFT calculations were performed using the $\mathrm{Q}-$ Chem software package. ${ }^{76}$ Spectra were produced by convoluting the calculated energies and oscillator strengths with Gaussian functions with a full-width at half maximum of $0.5 \mathrm{eV}$. A constant shift of $5.9 \mathrm{eV}$ was applied to the calculated excitation energies for sulfur to account for relativistic effects, consistent with previous studies. ${ }^{77}$

\section{Results and Discussion}

\subsection{Experimental NEXAFS spectroscopy}

High quality $S$ 1s and $N$ 1s NEXAFS spectra with sharp peaks were obtained for all investigated ILs. For both the $S 1 \mathrm{~S}$ and $\mathrm{N}$ 1s edges, a wide range of spectral shapes and experimental NEXAFS white line energies, $E_{W L}(\exp )$, were recorded, reflecting the wide range of both sulfur and nitrogen bonding environments in the ILs studied (see Tables S2 and S3). A comprehensive analysis of the $E_{W L}(\exp )$ values will be discussed in detail in other publications ${ }^{62,63}$.

ILs containing imidazolium cations and anions of the form [YSO $]^{-}$(i.e. $\left[\mathrm{NTf}_{2}\right]^{-},\left[\mathrm{TfO}^{-}\right.$, $\left[\mathrm{MeSO}_{3}\right]^{-},\left[\mathrm{MeSO}_{4}\right]^{-}$and $\left.\left[\mathrm{HSO}_{4}\right]^{-}\right)$were found to have similar $\mathrm{S}$ 1s near-edge structure, exhibiting one broad peak, or in the case of $\left[\mathrm{MeSO}_{4}\right]^{-}$two broad peaks with a small separation (Figure 1). This similarity suggests that the orbitals that give rise to these peaks are of a similar nature, which is expected considering the similar geometries and covalent bonds of the $\left[\mathrm{YSO}_{x}\right]^{-}$anions. For both $\left[\mathrm{NTf}_{2}\right]^{-}$and [TfO] $]^{-}$an additional small, broad peak is present at $\sim 2487 \mathrm{eV}$, which can be assigned to the $\mathrm{S}-\mathrm{CF}_{3}$ group, since no peak at similar energy was observed for any other $\left[\mathrm{YSO}_{x}\right]^{-} \mathrm{S} 1 \mathrm{~s}$ spectra).

For $\left[\mathrm{S}_{2,2,2}\right]\left[\mathrm{NTf}_{2}\right]$, the only IL studied here that contains sulfur atoms in two different covalently bonded environments, two separate peaks were observed at $E_{\mathrm{WL}}(\exp )=2475.8$ $\mathrm{eV}$ and $E_{\mathrm{WL}}(\exp )=2480.8 \mathrm{eV}$ (Figure 1 and Figure $3 \mathrm{~b}$ ), which can be attributed to the cation and anion respectively (plus a peak at $\sim 2487 \mathrm{eV}$ due to the $\mathrm{S}-\mathrm{CF}_{3}$ group). The peak at $2480.8 \mathrm{eV}$ can be assigned to the $\left[\mathrm{NTf}_{2}\right]^{-}$anion based on a comparison with the $\left[\mathrm{C}_{8} \mathrm{C}_{1} \mathrm{Im}\right]\left[\mathrm{NTf}_{2}\right] \mathrm{S}$ 1s NEXAFS spectrum (Figure 1, $\left.E_{\mathrm{WL}}(\exp )=2481.1 \mathrm{eV}\right)$. The peak at $E_{\mathrm{WL}}=$ $2475.8 \mathrm{eV}$ arises from the $\left[S_{2,2,2}\right]^{+}$cation, with a less intense shoulder at $2477.5 \mathrm{eV}$. Both $E_{\mathrm{WL}}$ and the shoulder energy match very well to aqueous $\left[\mathrm{S}_{1,1,1}\right]^{+}{ }^{28}$ In addition, the $E_{\mathrm{WL}}$ closely matches the S 1s X-ray photoelectron electron binding energy of $2474.6 \mathrm{eV}$ for $\left[\mathrm{S}_{2,2,2}\right]^{+}$in $\left[\mathrm{S}_{2,2,2}\right]\left[\mathrm{NTf}_{2}\right]^{63}$ Features at $h v>\sim 2478 \mathrm{eV}$ that are due to the $\left[\mathrm{S}_{2,2,2}\right]^{+}$ion for $\left[\mathrm{S}_{2,2,2}\right]\left[\mathrm{NTf}_{2}\right]$ were not discernible owing to the presence of peaks from $\left[\mathrm{NTf}_{2}\right]^{-}$. $E_{\mathrm{WL}}(\exp )$ for $\mathrm{S}_{8}$ and several of our IL anions are in excellent agreement with the literature values of $E_{\mathrm{WL}}(\exp )$ (see Supplementary Information for more details), demonstrating that our energy calibration for the $S$ 1s NEXAFS results is reliable. 


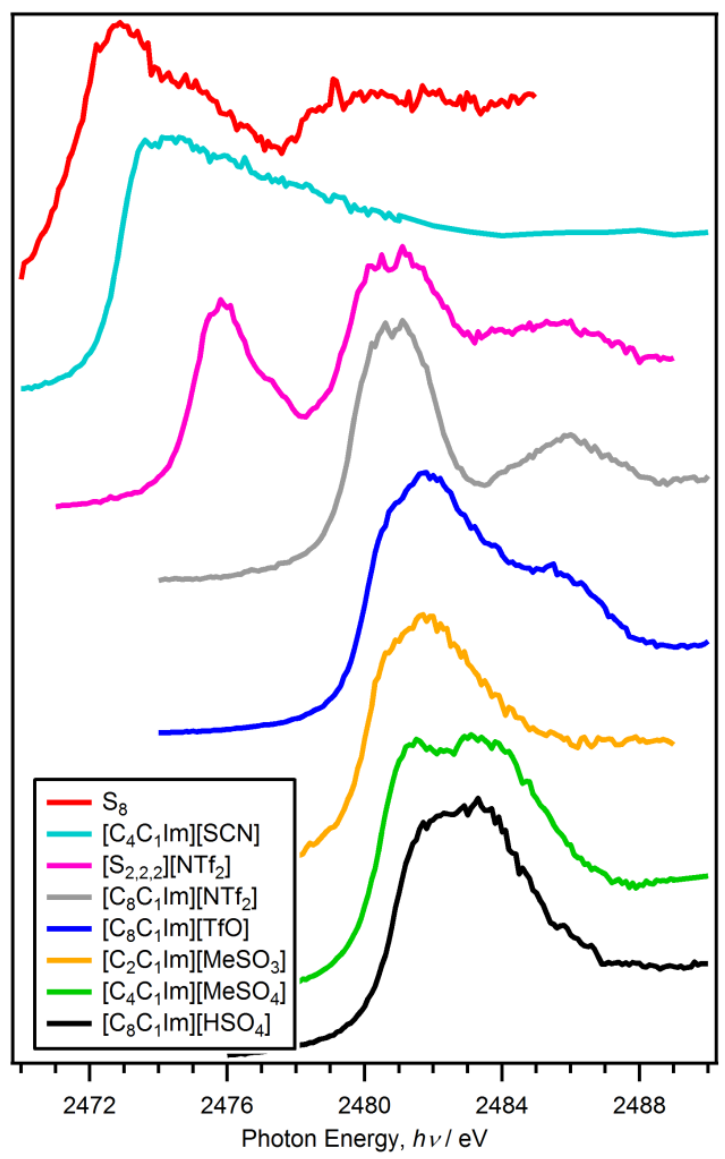

Figure 1. Experimental $S$ 1s edge NEXAFS spectra for seven ILs and elemental sulfur $\left(S_{8}\right)$ using fluorescence yield (FY) detection (the $S_{8}$ spectrum shows the spectral shape expected when self-absorption occurs for FY detection). The spectra are vertically offset for clarity.

For the four ILs studied here that contain an aprotic imidazolium cation $\left(\left[\mathrm{C}_{8} \mathrm{C}_{1} \mathrm{Im}\right] \mathrm{Cl}\right.$, $\left[\mathrm{C}_{4} \mathrm{C}_{1} \mathrm{Im}\right][\mathrm{SCN}],\left[\mathrm{C}_{8} \mathrm{C}_{1} \mathrm{Im}\right]\left[\mathrm{NTf} \mathrm{f}_{2}\right]$ and $\left.\left[\mathrm{C}_{8} \mathrm{C}_{1} \mathrm{Im}\right]\left[\mathrm{C}(\mathrm{CN})_{3}\right]\right)$, the single peaks observed in the $\mathrm{N} 1 \mathrm{~s}$ NEXAFS spectra at $E_{\mathrm{WL}}(\exp ) \sim 401.8 \mathrm{eV}$ can be assigned to the cationic nitrogen atoms. This finding is confirmed by the single peak observed in the $\mathrm{N} 1 \mathrm{~s}$ spectrum for $\left[\mathrm{C}_{8} \mathrm{C}_{1} \mathrm{Im}\right] \mathrm{Cl}$ (Figure 2), an IL which contains only cationic nitrogen. This peak is expected to arise from an $\mathrm{N} 1 \mathrm{~s} \rightarrow \pi^{*}$ transition. ${ }^{38,39}$ The presence of a single peak for $\left[\mathrm{C}_{8} \mathrm{C}_{1} \mathrm{Im}\right] \mathrm{Cl}$ means that the two nitrogen atoms in imidazolium cannot be distinguished using NEXAFS spectroscopy due to the peaks occurring at essentially the same energies (better experimental energy resolution is unlikely to lead to detection of two peaks), consistent with literature reports. ${ }^{35-40}$ Our measured $E_{\mathrm{WL}}(\exp ) \sim 401.8 \mathrm{eV}$ is in excellent agreement with the literature value of $\sim 401.9 \mathrm{eV},{ }^{33,35-40}$ and the energy calibration for the $\mathrm{N} 1 \mathrm{~s}$ NEXAFS results is reliable.

For the protic ammonium ILs $\left(\left[\mathrm{N}_{2,2,1,0}\right][\mathrm{TfO}]\right.$ and $\left.\left[\mathrm{N}_{4,1,1,0}\right]\left[\mathrm{HSO}_{4}\right]\right)$, the $\mathrm{N}$ 1s peaks $\left(E_{\mathrm{WL}}(\exp )\right.$ $\sim 405.8 \mathrm{eV}$ ) can be assigned to $\mathrm{N} 1 \mathrm{~s} \rightarrow \sigma^{*}$ transitions. This assignment is made based on the significantly higher $E_{\mathrm{WL}}(\exp )$, relative to the $E_{\mathrm{WL}}(\exp )$ observed for imidazoliumcontaining ILs.

For ILs with either $[\mathrm{SCN}]^{-}$or $\left[\mathrm{C}(\mathrm{CN})_{3}\right]^{-}$anions, $\mathrm{N}$ 1s X-ray photoelectron (XP) spectra and calculated nitrogen atomic charges strongly suggest that the peaks with energy $<400 \mathrm{eV}$ are due to $\mathrm{N} 1 \mathrm{~s} \rightarrow \pi^{*}$ transitions for the anions. ${ }^{62} \quad\left[\mathrm{C}_{4} \mathrm{C}_{1} \mathrm{Im}\right][\mathrm{SCN}]$ gives a single Gaussianshaped peak due to the anion at $E_{\mathrm{WL}}(\exp )=399.5 \mathrm{eV}$ (Figure 2 and Figure 6b), whereas the anion in $\left[\mathrm{C}_{8} \mathrm{C}_{1} \mathrm{Im}\right]\left[\mathrm{C}(\mathrm{CN})_{3}\right]$ gives two peaks at $E_{\mathrm{WL}}(\exp )=399.0 \mathrm{eV}$ and $E_{\mathrm{WL}}(\exp )=401.1 \mathrm{eV}$ (Figure 2 and Figure $3 a$ ). For $\left[\mathrm{P}_{6,6,6,14}\right]\left[\mathrm{NO}_{3}\right]$, the single peak at $E_{\mathrm{WL}}(\exp )=405.1 \mathrm{eV}$ can be assigned to an anionic $\mathrm{N} 1 \mathrm{~s} \rightarrow \pi^{*}$ transition (Figure 2). This observation is consistent with $\mathrm{N}$ 
1s XP spectra and nitrogen atomic charges (broadly, more positive atomic charges lead to larger $\left.E_{\mathrm{WL}}\right)^{62}$ The spectrum of $\left[\mathrm{C}_{8} \mathrm{C}_{1} \mathrm{Im}\right]\left[\mathrm{NTf}_{2}\right]($ Figure 2) has two additional peaks compared with literature $\mathrm{N} 1 \mathrm{~s}$ spectra. ${ }^{37-39}$ These peaks likely arise from a relatively small amount of $\mathrm{X}$-ray beam damage, as the sample had been exposed to the X-rays for eight hours when the spectrum was recorded. Therefore, the experimental $N$ 1s NEXAFS spectrum for the $\left[\mathrm{NTf}_{2}\right]^{-}$anion is currently unknown. The best approach would be to study an IL that contains no nitrogen in the cation, e.g. $\left[\mathrm{P}_{6,6,6,14}\right]\left[\mathrm{NTf}_{2}\right]$; we used this approach to positively identify peaks due to the $\left[\mathrm{NO}_{3}\right]^{-}$anion for $\left[\mathrm{P}_{6,6,6,14}\right]\left[\mathrm{NO}_{3}\right]$.

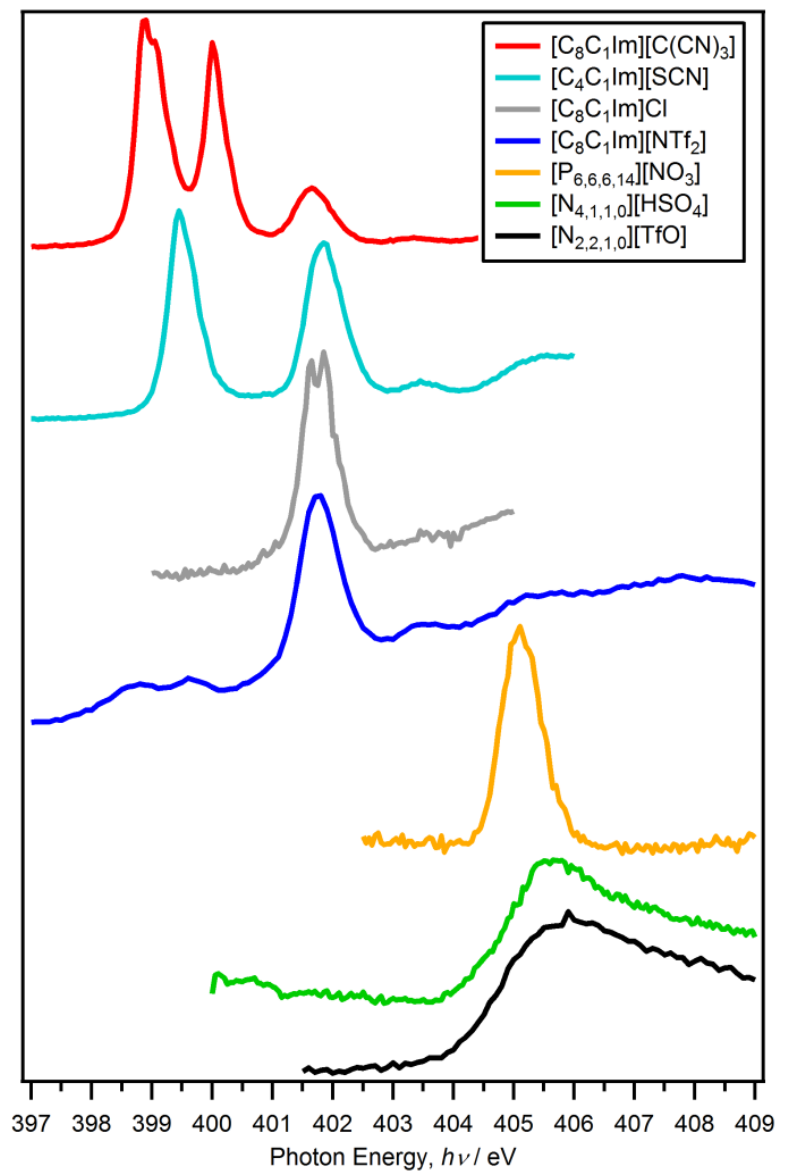

Figure 2. Experimental $\mathrm{N}$ 1s edge NEXAFS spectra for seven ILs using partial electron yield (PEY) detection. The features at $h v<400 \mathrm{eV}$ for $\left[\mathrm{C}_{8} \mathrm{C}_{1} \mathrm{Im}\right]\left[\mathrm{NTf} \mathrm{f}_{2}\right]$ are most likely due to sample damage (see text). The spectra are vertically offset for clarity.

The presence of well-resolved and readily identifiable cation peaks and anion peaks make $\left[\mathrm{C}_{n} \mathrm{C}_{1} \mathrm{Im}\right]\left[\mathrm{C}(\mathrm{CN})_{3}\right]$ and $\left[\mathrm{C}_{4} \mathrm{C}_{1} \mathrm{Im}\right][\mathrm{SCN}] \mathrm{ILs}$ better than $\left[\mathrm{C}_{n} \mathrm{C}_{1} \mathrm{Im}\right]\left[\mathrm{NTf}_{2}\right] \mathrm{ILs}^{38,39}$ for testing the quality of calculated $\mathrm{N}$ 1s NEXAFS spectra. These peaks allow a test of the relative accuracy of TD-DFT calculations for cations and anions. In addition, $\left[\mathrm{S}_{2,2,2}\right]\left[\mathrm{NTf}_{2}\right]$ is a very good IL for testing the quality of calculated S 1s NEXAFS spectra owing to the well-resolved peaks for both the cation and anion.

There is no significant counterion dependence observed for any of the $S$ is or $N$ 1s data recorded here. $S$ 1s NEXAFS spectra for all four $\left[\mathrm{C}_{n} \mathrm{C}_{1} I \mathrm{~m}\right]\left[\mathrm{NTf} \mathrm{f}_{2}\right] \mathrm{ILs}$ were similar in terms of both the relative peak areas and energies (Figure S2). In addition, the PEY S 1s NEXAFS spectra for $\left[\mathrm{C}_{8} \mathrm{C}_{1} / \mathrm{m}\right]\left[\mathrm{NTf}_{2}\right]$ and $\left[\mathrm{N}_{4,1,1,1}\right]\left[\mathrm{NTf}_{2}\right]$ were essentially identical (Figure S3), confirming a lack of counter-cation dependence. Lastly, for three [cation] $\left[\mathrm{HSO}_{4}\right]$ ILs, we have previously published the lack of counterion dependence. ${ }^{43}$ Comparing the $\mathrm{N} 1 \mathrm{~s}$ spectra for the four imidazolium-based ILs, there is clearly little or no alkyl or anion dependence on either the peak energy or the peak shape for the cationic nitrogen. In 
addition, there is little or no alkyl or anion dependence on either $E_{\mathrm{WL}}(\exp )$ or the peak shape for $\left[\mathrm{N}_{4,1,1,0}\right]\left[\mathrm{HSO}_{4}\right]$ compared to $\left[\mathrm{N}_{2,2,1,0}\right][\mathrm{TfO}]$.

\subsection{Experimental versus calculated NEXAFS spectra: assessing the accuracy of TD-DFT calculations for a wide range of ILs}

Figures 3 to 6 show comparisons between calculated and experimental spectra. For the majority of the ILs, spectra calculated from the lowest energy ion pair conformer provide a good visual match for both $\mathrm{S} 1 \mathrm{~s}$ and $\mathrm{N} 1 \mathrm{~s}$ experimental spectra (see Figure $\mathrm{S} 5$ and Figure $\mathrm{S} 6$ for comparisons for all ILs). The only exception is the $\mathrm{N}$ 1s spectrum of $\left[\mathrm{C}_{4} \mathrm{C}_{1} \mathrm{Im}\right][\mathrm{SCN}]$, whereby calculations on the lowest energy ion pair conformer (Sf) lead to a small peak not observed experimentally (Figure 6). However, a slightly higher energy $\left(<10 \mathrm{~kJ} \mathrm{~mol}^{-1}\right)$ ion pair conformer gives an excellent match to the experimental $\mathrm{N} 1 \mathrm{~s}$ spectrum (discussed further in Section 3.3.3). It is possible that, despite its low energy, structures similar to Sf are relatively rare in the liquid phase and hence do not contribute significantly to the experimental NEXAFS spectra. Therefore, for all 14 samples studied, we found at least one low-energy ion pair conformer that gave a calculated NEXAFS spectrum that matched very well to the experimental NEXAFS spectrum.
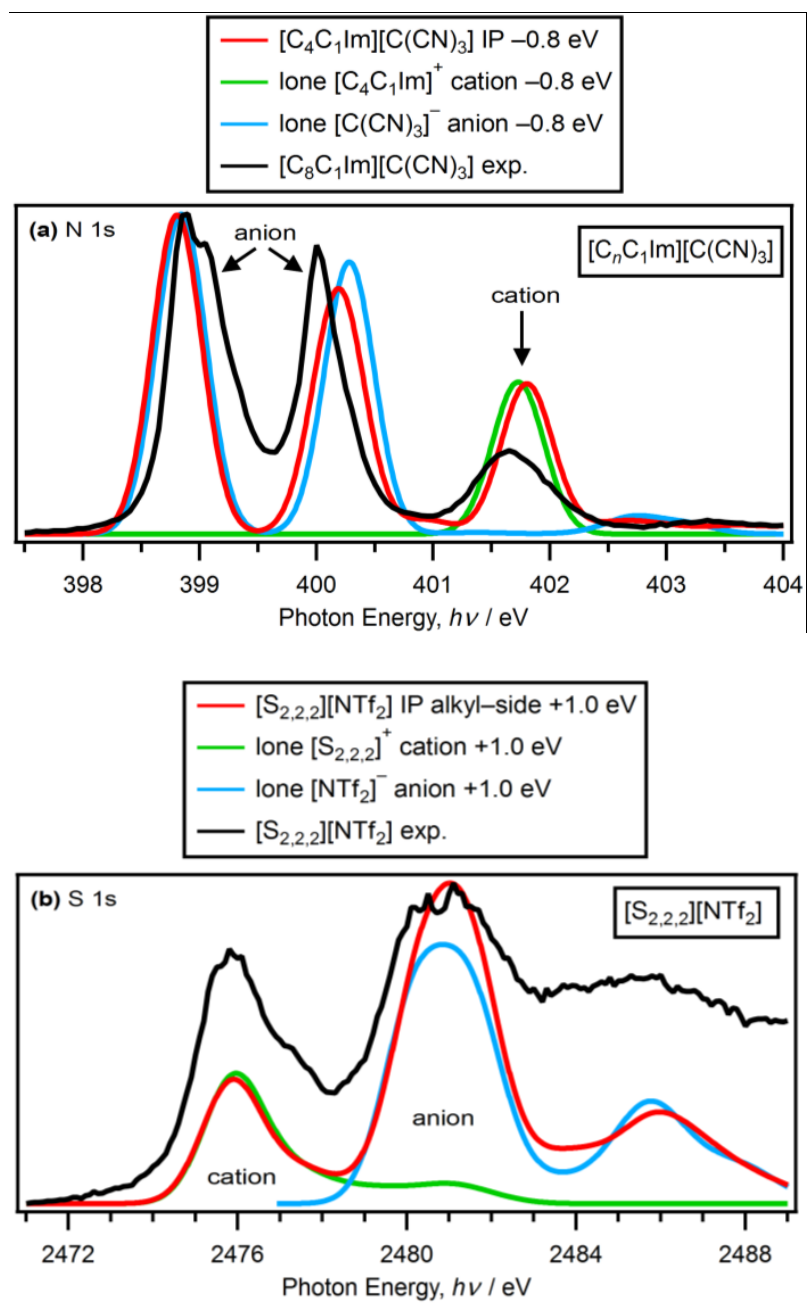

Figure 3. (a) Comparison of experimental and calculated $\mathrm{N}$ 1s NEXAFS spectra for an ion pair (IP) $\left[\mathrm{C}_{n} \mathrm{C}_{1} \mathrm{Im}\right]\left[\mathrm{C}(\mathrm{CN})_{3}\right]$ conformer and the lone ions. (b) Comparison of experimental and calculated $S$ 1s NEXAFS spectra for the $\left[\mathrm{S}_{2,2,2}\right]\left[\mathrm{NTf}_{2}\right]$ ion pair (IP) alkyl-side conformer $\left(\left[\mathrm{NTf}_{2}\right]^{-}\right.$sits further from the sulfur centre in the cation and interacts only with the alkyl chains $\left.{ }^{63}\right)$ and lone ions. Results for $\left[\mathrm{S}_{2,2,2}\right]\left[\mathrm{NTf}_{2}\right]$ lone ions are also shown. The "IP $-0.8 \mathrm{eV}$ " 
(and similar) means that the ion pair calculated NEXAFS spectrum has been shifted by -0.8 $\mathrm{eV}$.

To align the calculated spectra with experiment it is necessary to apply energy shifts to the calculated spectra, and the smaller the energy shift the better the calculations are performing in predicting the correct energy scale. The magnitudes of the shifts were determined by visually matching the calculated and experimental spectra (see Tables S4 and S5 for all energy shifts). No energy shift was required to match the calculated $S$ 1s spectrum to the experimental $\mathrm{S} 1 \mathrm{~s}$ spectrum for $\left[\mathrm{C}_{4} \mathrm{C}_{1} \mathrm{Im}\right][\mathrm{SCN}]$. For the six other ILs for which $\mathrm{S}$ 1s spectra were calculated $\left(\left[\mathrm{S}_{2,2,2}\right]\left[\mathrm{NTf}_{2}\right], \quad\left[\mathrm{C}_{4} \mathrm{C}_{1} \mathrm{Im}_{\mathrm{m}}\right]\left[\mathrm{NTf} \mathrm{N}_{2}\right], \quad\left[\mathrm{C}_{4} \mathrm{C}_{1} \mathrm{Im}\right][\mathrm{TfO}], \quad\left[\mathrm{C}_{4} \mathrm{C}_{1} \mathrm{Im}\right]\left[\mathrm{MeSO}_{3}\right]\right.$, $\left[\mathrm{C}_{4} \mathrm{C}_{1} \mathrm{Im}\right]\left[\mathrm{MeSO}_{4}\right]$ and $\left.\left[\mathrm{C}_{4} \mathrm{C}_{1} \mathrm{Im}\right]\left[\mathrm{HSO}_{4}\right]\right)$, the calculated spectra were shifted by $+1.2 \pm 0.2 \mathrm{eV}$ to match the experimental spectra. For four of the aprotic ILs $\left(\left[\mathrm{C}_{4} \mathrm{C}_{1} \operatorname{Im}\right]\left[\mathrm{C}(\mathrm{CN})_{3}\right]\right.$, $\left[\mathrm{C}_{4} \mathrm{C}_{1} \mathrm{Im}\right][\mathrm{SCN}],\left[\mathrm{C}_{4} \mathrm{C}_{1} \mathrm{Im}\right] \mathrm{Cl}$ and $\left.\left[\mathrm{C}_{4} \mathrm{C}_{1} I \mathrm{~m}\right]\left[\mathrm{NTf} \mathrm{f}_{2}\right]\right)$, the calculated $\mathrm{N}$ 1s spectra were shifted by $-0.8 \pm 0.2 \mathrm{eV}$ to match the experimental data. For $\left[\mathrm{P}_{6,6,6,14}\right]\left[\mathrm{NO}_{3}\right]$, an energy shift of $+0.8 \mathrm{eV}$ was required. For the two protic ILs studied ([ $\left.\mathrm{N}_{4,1,1,0}\right]\left[\mathrm{HSO}_{4}\right]$ and $\left.\left[\mathrm{N}_{2,2,1,0}\right][\mathrm{TfO}]\right)$, the $\mathrm{N} 1 \mathrm{~s}$ calculated spectra required energy shifts of $-0.4 \mathrm{eV}$ to match the experimental spectra. For a direct comparison, our energy shift for the calculated $\mathrm{N} 1 \mathrm{~s}$ spectrum of the most stable ion pair conformer of $\left[\mathrm{C}_{4} \mathrm{C}_{1} \mathrm{Im}\right]\left[\mathrm{NTf}_{2}\right]$ was $-0.8 \mathrm{eV}$, whereas Ehlert et al. using TP-DFT required an energy shift of $-1.6 \mathrm{eV}$ for their $\left[\mathrm{C}_{4} \mathrm{C}_{1} \mathrm{Im}\right]\left[\mathrm{NTf}_{2}\right]$ ion pair conformer ${ }^{38}$.

The excellent agreement between experiment and the calculated spectra for both energy and shape shows that TD-DFT is a suitable method for calculating NEXAFS spectra of ILs; in cases where there is a poorer visual match, the discrepancy can be attributed to the system size and/or conformer but not to the TD-DFT method. Comparing our TD-DFT method to the TP-DFT methods used previously for ILs, it is difficult to determine which method works best because so few ILs have been studied using the TP-DFT method. However, we can state with confidence that our TD-DFT method provides an excellent match to experiments, with small energy shifts required. The fact that the energy shifts required to match experiments were very similar for lone ions and ion pairs suggests that the energy shifts are required because of the method and not the system size.

\subsection{Investigating the model system: size and structure}

We now explore the dependence of the calculated spectra on the model system used in the calculations. We investigated the sensitivity of calculated spectra to both the system size (Ione ion, ion pair and ion pair dimer) and system conformation. Investigating the system size dependence provides insight into both the degree of excited state localisation and the importance of intermolecular interactions for IL NEXAFS spectra; if lone ions calculations can reproduce NEXAFS spectra then clearly intermolecular interactions are unimportant, and the excited states must be localised on a single ion. Our investigation into system conformation (structure) is mainly for practical purposes; we wish to determine whether multiple conformers are required to calculate IL NEXAFS spectra (use of a single conformer would lead to significant computational savings).

\subsubsection{Size and structure do not matter: most ILs}

Calculations on lone ions were sufficient to obtain a satisfactory match to experimental data for eight out of the $12 \mathrm{ILs}$ studied: $\left[\mathrm{S}_{2,2,2}\right]\left[\mathrm{NTf} \mathrm{T}_{2}\right], \quad\left[\mathrm{C}_{4} \mathrm{C}_{1} \mathrm{Im}\right][\mathrm{TfO}], \quad\left[\mathrm{C}_{4} \mathrm{C}_{1} \mathrm{Im}\right]\left[\mathrm{MeSO}_{4}\right]$, $\left[\mathrm{C}_{4} \mathrm{C}_{1} \mathrm{Im}\right]\left[\mathrm{HSO}_{4}\right], \quad\left[\mathrm{C}_{4} \mathrm{C}_{1} / \mathrm{m}\right]\left[\mathrm{NTf}_{2}\right], \quad\left[\mathrm{P}_{6,6,6,14}\right]\left[\mathrm{NO}_{3}\right], \quad\left[\mathrm{C}_{4} \mathrm{C}_{1} \mathrm{Im}\right] \mathrm{Cl}$ and $\left[\mathrm{C}_{4} \mathrm{C}_{1} \mathrm{Im}\right]\left[\mathrm{C}(\mathrm{CN})_{3}\right]$. For example, Figure 3 shows the excellent matches between experiment and lone ion calculations for $\left[\mathrm{S}_{2,2,2}\right]\left[\mathrm{NTf}_{2}\right]$ and $\left[\mathrm{C}_{n} \mathrm{C}_{1} \operatorname{lm}\right]\left[\mathrm{C}(\mathrm{CN})_{3}\right]$. The presence of peaks from both the anion and cation in these NEXAFS spectra makes the match particularly impressive, as it shows that calculations capture the differences in energy between cation and anion excitations. Further evidence of lone ions being sufficient for eight of 12 ILs is displayed in Figure S7 and Figure S8, which shows lone ion and ion pair calculations leading to highly 
similar calculated spectra. The success of lone ion calculations for these eight ILs suggests the excited states are relatively localised on the ion which contains the (either $S$ 1s or N 1s) core-hole (if excitations were delocalised onto the counterion, then lone ions calculations would not be able to describe them).

\subsubsection{Structure matters: $\left[\mathrm{C}_{4} \mathrm{C}_{1} I \mathrm{~m}\right] \mathrm{Cl}$}

For $\left[\mathrm{C}_{4} \mathrm{C}_{1} \mathrm{Im}\right] \mathrm{Cl}$, the calculated $\mathrm{N}$ 1s spectra for two of the three ion pair conformers (front and top) give a single peak, providing a good visual match with the experimental spectrum (Figure 4a). These two ion pair conformers have the $\mathrm{Cl}^{-}$anion located near the imidazolium $\mathrm{C}^{2}-\mathrm{H}$ and approximately equidistant from the two imidazolium nitrogen atoms (Figure $4 \mathrm{c}, \mathrm{Cl}-$ $\mathrm{N}$ distances range from $3.2 \AA$ to $4.2 \AA$ ).

However, one $\left[\mathrm{C}_{4} \mathrm{C}_{1} \mathrm{Im}\right] \mathrm{Cl}$ ion pair conformer (the back-butyl) gives two peaks in the calculated $\mathrm{N}$ 1s spectrum, which is not observed in the $\left[\mathrm{C}_{8} \mathrm{C}_{1} \mathrm{Im}\right] \mathrm{Cl}$ experimental spectrum (Figure 4b). For this back-butyl conformer the $\mathrm{Cl}^{-}$anion is located much further from one of the imidazolium nitrogen atoms than the other nitrogen atom (Figure $4 \mathrm{c}, \mathrm{Cl}-\mathrm{N}\left(\mathrm{CH}_{3}\right)$ distance $=5.4 \AA$ and $\mathrm{Cl}-\mathrm{N}\left(\mathrm{C}_{4} \mathrm{H}_{9}\right)$ distance $=3.7 \AA$ ); hence, the nitrogen atoms have very different electronic environments. The peak at lower $h v$ can be assigned to the $\mathrm{Cl}-\mathrm{N}\left(\mathrm{CH}_{3}\right)$ nitrogen atom and the peak at higher $h v$ can be assigned to the $\mathrm{Cl}-\mathrm{N}\left(\mathrm{C}_{4} \mathrm{H}_{9}\right)$ nitrogen atom by analysing the individual contributions of each atom to the calculated spectrum. Clearly, this back-butyl ion pair conformer does not capture the interactions present in the bulk IL, which is unsurprising given the high relative energy of the back-butyl conformer $\left(\sim 41 \mathrm{~kJ} \mathrm{~mol}^{-1}\right.$ higher in energy than the most stable conformer). Nevertheless, the calculated spectrum with two peaks for $\mathrm{N} 1 \mathrm{~s} \rightarrow \pi^{*}$ transitions for the back-butyl conformer is very similar to that observed experimentally for solid $\left[\mathrm{C}_{1} \mathrm{C}_{0} \mathrm{Im}\right] \mathrm{Cl}^{37}$ This match suggests solid $\left[\mathrm{C}_{1} \mathrm{C}_{0} \mathrm{Im}\right] \mathrm{Cl}$ has very different $\mathrm{Cl}-\mathrm{N}$ interactions for the two different $\mathrm{N}$ atoms in $\left[\mathrm{C}_{1} \mathrm{C}_{0} \mathrm{Im}\right]^{+}$.
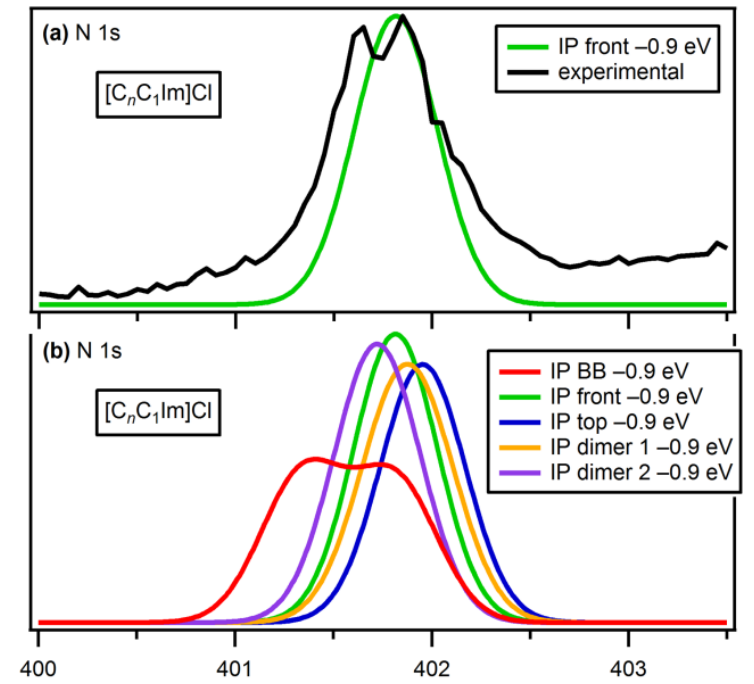

(c)

Photon Energy, $h v / \mathrm{eV}$

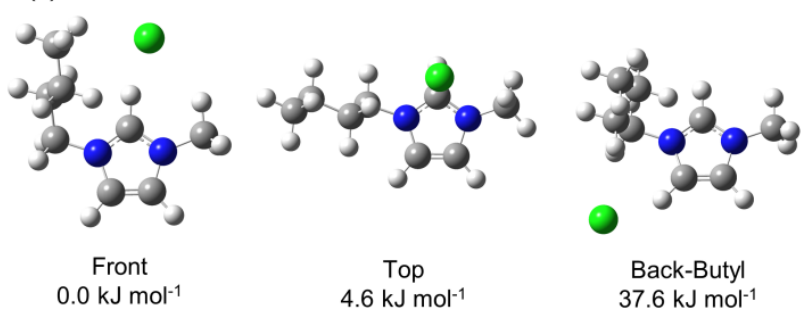

Figure 4. (a) Comparison of the experimental $N$ 1s NEXAFS spectrum for $\left[\mathrm{C}_{8} \mathrm{C}_{1} I \mathrm{~m}\right] \mathrm{Cl}$ and the calculated $\mathrm{N} 1 \mathrm{~s}$ NEXAFS spectrum for the $\left[\mathrm{C}_{4} \mathrm{C}_{1} \mathrm{Im}\right] \mathrm{Cl}$ ion pair (IP) front conformer. (b) Calculated $\mathrm{N}$ 1s NEXAFS spectra for $\left[\mathrm{C}_{n} \mathrm{C}_{1} \mathrm{Im}\right] \mathrm{Cl}$ for three IP conformers and two IP dimer 
conformers. (c) Structures of the three IP conformers studied here for $\left[C_{4} C_{1} I m\right] C l$. BB $=$ back-butyl conformer. Values in (c) are relative zero point-energy corrected energies. Pictures of IP dimer conformers are shown in Figure S22 (IP dimer 1 = D_FF_TT_T, IP dimer $2=$ M_BF_FB_A). The "front $-0.9 \mathrm{eV}$ " means the front conformer with a shift of -0.9 $\mathrm{eV}$ applied to the calculated spectrum.

Calculations were performed for $\left[\mathrm{C}_{2} \mathrm{C}_{1} \mathrm{Im}\right] \mathrm{Cl}$ ion pair dimers. The butyl chain was replaced with an ethyl group to reduce the computational cost; this change is not expected to have a significant impact on the results (as we demonstrated using our experimental data in Section 3.1). For six different $\left[\mathrm{C}_{2} \mathrm{C}_{1} \mathrm{Im}\right] \mathrm{Cl}$ ion pair dimer conformers (Figure S22) all $\mathrm{N} 1 \mathrm{~s}$ calculated NEXAFS spectra give a single peak, in agreement with the $\left[\mathrm{C}_{8} \mathrm{C}_{1} \mathrm{Im}\right] \mathrm{Cl}$ experimental spectrum. Therefore, as expected, the ion pair dimers capture the interactions present in the bulk IL well.

\subsubsection{Size and structure matter: $\left[\mathrm{N}_{4,1,1,0}\right]\left[\mathrm{HSO}_{4}\right], \quad\left[\mathrm{N}_{2,2,1,0}\right][\mathrm{TfO}]$ and $\left[\mathrm{C}_{4} \mathrm{C}_{1} \mathrm{Im}\right][\mathrm{SCN}]$}

For both $\left[\mathrm{N}_{4,1,1,0}\right]\left[\mathrm{HSO}_{4}\right]$ and $\left[\mathrm{N}_{2,2,1,0}\right][\mathrm{TfO}]$, selected ion pair conformers gave good visual matches with experiment (Figure 5a and Figure S6d). These conformers, labelled here as $\mathrm{NH}-\mathrm{O}$ conformers, have the anion located on the $\mathrm{N}-\mathrm{H}$ side of the cation, allowing a strong cation-anion hydrogen bond to form (Figure $5 \mathrm{c}$ ). For both $\left[\mathrm{N}_{4,1,1,0}\right]\left[\mathrm{HSO}_{4}\right]$ and $\left[\mathrm{N}_{2,2,1,0}\right][\mathrm{TfO}]$, certain ion pair conformers and the lone protic cation gave poor visual matches with experiment (Figure 5b and Figure S6d), all showing two well separated peaks, with the peak at larger $h v$ having a much larger relative intensity. These conformers, labelled here as alkyl-O ion pair conformers, have the anion located near the alkyl chains, meaning that a hydrogen bond to the cationic NH group cannot be formed (Figure 5c).

The $\mathrm{NH}-\mathrm{O}$ conformers show the best match to experiment as these structures involve delocalisation of the excited state over both cation and anion. The LUMO to LUMO+4 (which contribute strongly to the calculated spectra) are delocalised across both ions for $\mathrm{NH}-\mathrm{O}$ conformers, but localised on the cation for alkyl-O conformers (Figure S9). Therefore, the formation of strong $\mathrm{N}-\mathrm{H}^{\cdots} \mathrm{O}$ hydrogen bonds significantly affects the $\mathrm{N}$ 1s NEXAFS spectrum, and must be accounted for when calculating NEXAFS spectra for protic ILs (i.e. by using ion pair systems as a minimum). 

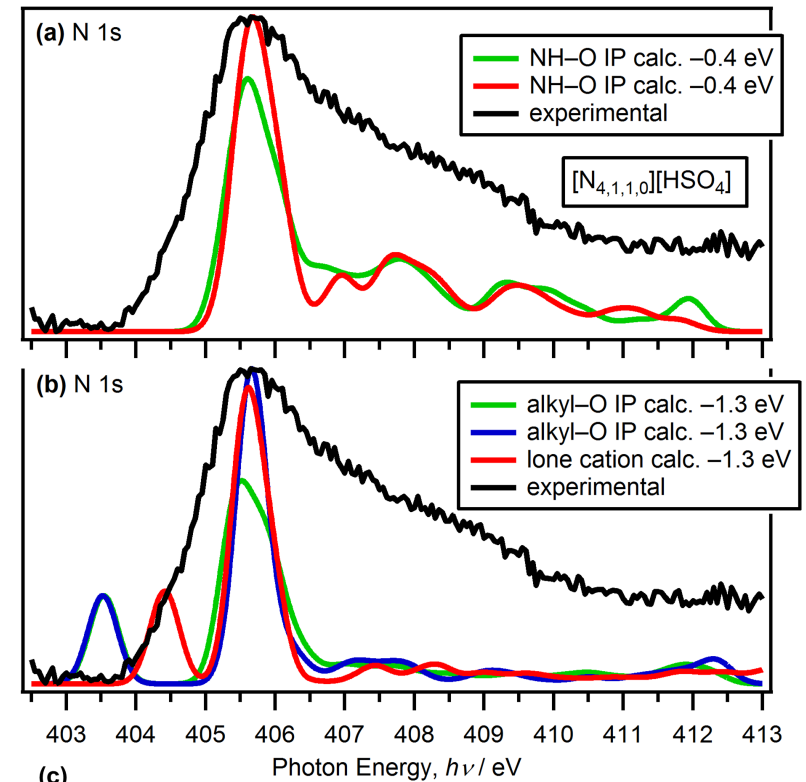

(c)

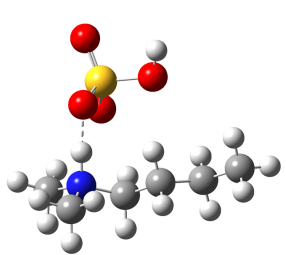

$\mathrm{NH}-\mathrm{O}$

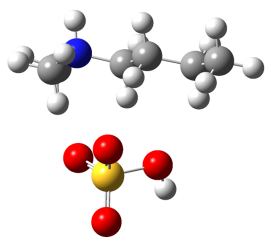

Alkyl-O

Figure 5. (a) Comparison of experimental and calculated $N$ 1s NEXAFS spectra for $\left[\mathrm{N}_{4,1,1,0}\right]\left[\mathrm{HSO}_{4}\right]$ for two $\mathrm{NH}-\mathrm{O}$ ion pair (IP) conformers. (b) Comparison of experimental and calculated $\mathrm{N}$ 1s NEXAFS spectra for $\left[\mathrm{N}_{4,1,1,0}\right]\left[\mathrm{HSO}_{4}\right]$ for two alkyl-O ion pair (IP) conformers and lone $\left[\mathrm{N}_{4,1,1,0}\right]^{+}$. (c) Structures of two ion pair conformers for $\left[\mathrm{N}_{4,1,1,0}\right]\left[\mathrm{HSO}_{4}\right]$. The "calc. $1.3 \mathrm{eV}$ " (and similar) means the calculated spectrum was shifted by $-1.3 \mathrm{eV}$.

Calculations for lone $[\mathrm{SCN}]^{-}$gave a good match to the $\left[\mathrm{C}_{4} \mathrm{C}_{1} \mathrm{Im}\right][\mathrm{SCN}]$ experiment for the $\mathrm{N}$ $1 \mathrm{~s}$ edge (Figures $6 \mathrm{~b}$ and $6 \mathrm{c}$ ) but not for the $\mathrm{S} 1 \mathrm{~s}$ edge (Figure $6 \mathrm{a}$ ). In contrast, significant ion pair conformer dependence was observed for calculations for $\left[\mathrm{C}_{4} \mathrm{C}_{1} I \mathrm{~m}\right][\mathrm{SCN}]$ on the $\mathrm{N} 1 \mathrm{~s}$ edge (Figure $6 \mathrm{c}$ ) and not for calculations on the $\mathrm{S} 1 \mathrm{~s}$ edge (Figure $6 \mathrm{a}$ ). For $\left[\mathrm{C}_{4} \mathrm{C}_{1} I \mathrm{~m}\right][\mathrm{SCN}]$, the connection between calculated spectra and geometric structure is less obvious than for the protic ILs and $\left[\mathrm{C}_{4} \mathrm{C}_{1} \mathrm{Im}\right] \mathrm{Cl}$. At this stage these observations are difficult to rationalise using the different $\left[\mathrm{C}_{4} \mathrm{C}_{1} \mathrm{Im}\right][\mathrm{SCN}]$ structures.

$S 1 \mathrm{~s}$ calculated spectra for the three $\left[\mathrm{C}_{4} \mathrm{C}_{1} \mathrm{Im}\right][\mathrm{SCN}]$ ion pair conformers show no significant conformer dependence and give a satisfactory match to the experimental $S$ is spectrum (Figure 6a). The $S$ 1s calculated spectrum for the lone $[\mathrm{SCN}]^{-}$ion was poor with a sharp, intense peak at $\sim 2482 \mathrm{eV}$ that is not observed in either ion pair calculated spectra or the experimental spectrum (Figure 6a). We expect that the excited states include significant delocalisation onto the $\left[\mathrm{C}_{4} \mathrm{C}_{1} \mathrm{Im}\right]^{+}$countercation in this case.

The three $\left[\mathrm{C}_{4} \mathrm{C}_{1} \mathrm{Im}\right][\mathrm{SCN}]$ ion pair conformers investigated lead to three significantly different anionic $\mathrm{N}$ 1s calculated spectra (Figure 6c). There is an excellent visual match of the experimental $\mathrm{N}$ 1s spectrum with the calculated $\mathrm{N}$ 1s spectrum for one $\left[\mathrm{C}_{4} \mathrm{C}_{1} \mathrm{Im}\right][\mathrm{SCN}]$ ion pair conformer, CNbot (Figure 6b), and indeed with a calculated $\mathrm{N}$ 1s spectrum for lone $[\mathrm{SCN}]^{-}$. This CNbot conformer, in which the anionic nitrogen atom is located to the front of the imidazolium $\mathrm{C}^{2}-\mathrm{H}$ group (Figure $6 \mathrm{~d}$ ), leads to a calculated spectrum with a single sharp peak at $h v \sim 399 \mathrm{eV}$. However, the other two ion pair conformers, $\mathrm{Nf}$ and $\mathrm{Sf}$, give poorer 
matches (Figure 6c), as the shape of the feature due to the anion at $h v \sim 399 \mathrm{eV}$ does not match the relatively sharp peak in the $\left[\mathrm{C}_{4} \mathrm{C}_{1} \mathrm{Im}\right][\mathrm{SCN}]$ experimental spectrum. The $\mathrm{Sf}$ conformer, in which the anionic nitrogen atom sits directly above the imidazolium ring (Figure $6 \mathrm{~d}$ ), gives rise to a second peak $\sim 1 \mathrm{eV}$ lower in energy than the main peak. The calculated spectrum for the $\mathrm{Nf}$ conformer, in which the nitrogen atom sits above the $\mathrm{C}^{2}-\mathrm{H}$ group (Figure $6 \mathrm{~d}$ ), gives a much broader peak than both the calculated $\mathrm{N} 1 \mathrm{~s}$ spectrum for the CNbot conformer and the $\mathrm{N}$ 1s experimental spectrum. A tentative conclusion is that the poorest match to experiment occurs for conformers in which anionic nitrogen is located closer to the imidazolium ring $\pi-$ system. Note that the relative energies of all three $\left[\mathrm{C}_{4} \mathrm{C}_{1} \mid \mathrm{m}\right][\mathrm{SCN}]$ conformers are within $10 \mathrm{~kJ} \mathrm{~mol}^{-1}$, hence they should all be accessible in the liquid phase.
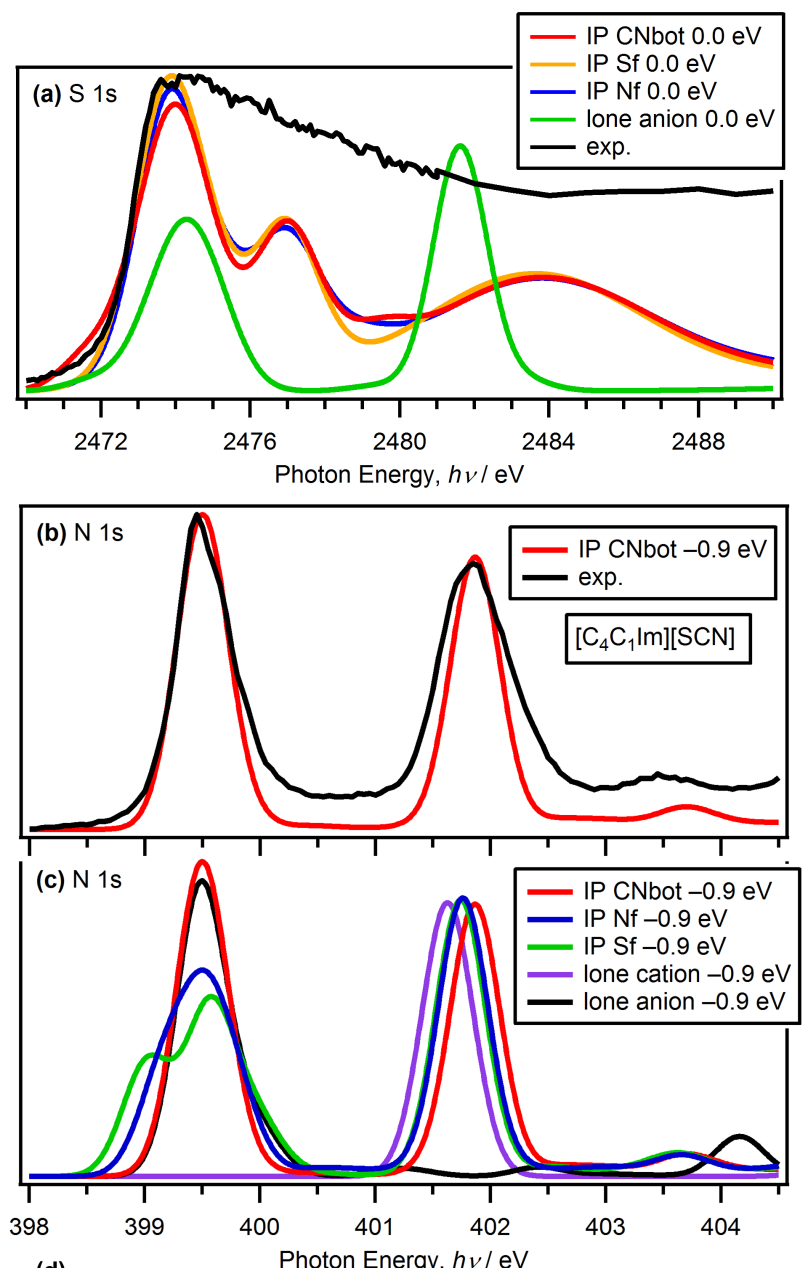

(d)

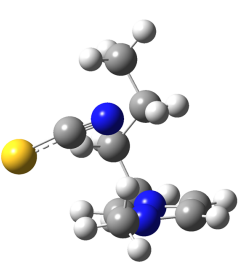

$\mathrm{Sf}$

$0.0 \mathrm{~kJ} \mathrm{~mol}^{-1}$

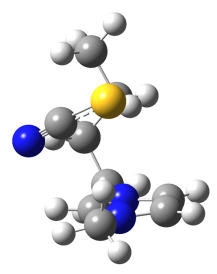

$\mathrm{Nf}$

$1.7 \mathrm{~kJ} \mathrm{~mol}^{-1}$

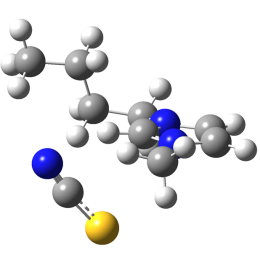

CNbot2 $9.6 \mathrm{~kJ} \mathrm{~mol}^{-1}$

Figure 6. Comparison of experimental and calculated NEXAFS spectra for $\left[\mathrm{C}_{4} \mathrm{C}_{1} \mid \mathrm{m}\right][\mathrm{SCN}]$ : (a) $\mathrm{S} 1 \mathrm{~s}$ edge, (b) $\mathrm{N} 1 \mathrm{~s}$ edge. (c) $\mathrm{N}$ 1s calculated NEXAFS spectra for three different $\left[\mathrm{C}_{4} \mathrm{C}_{1} \mathrm{Im}\right][\mathrm{SCN}]$ ion pairs (IP), lone $\left[\mathrm{C}_{4} \mathrm{C}_{1} \mathrm{Im}\right]^{+}$and lone [SCN] $]^{-}$. (d) Structures of the three ion pair conformers studied here for $\left[\mathrm{C}_{4} \mathrm{C}_{1} \mathrm{Im}\right][\mathrm{SCN}]$. Values in (d) are relative zero point-energy 
corrected energies. The term "IP CNbot $-0.9 \mathrm{eV}$ " (and similar) mean an ion pair structure whereby the calculated spectrum has been shifted $-0.9 \mathrm{eV}$.

\subsection{NEXAFS calculations for ILs: why the solvation environment does not play a significant role}

The ability to calculate accurate NEXAFS spectra using lone ions suggests that the solvation environment does not affect IL NEXAFS spectra (Section 3.3.1). This finding may seem to contradict other work suggesting that IL orbital energies strongly depend on the solvation environment; for example, calculations suggest that adding a $\left[\mathrm{C}_{4} \mathrm{C}_{1} \mathrm{Im}\right]^{+}$counterion to lone $\left[\mathrm{C}(\mathrm{CN})_{3}\right]^{-}$(i.e. using an ion pair) causes a $3.6 \mathrm{eV}$ shift in the highest occupied molecular orbital energy. ${ }^{47}$ In contrast, calculated anionic $E_{\mathrm{WL}}$ shifts by $<0.1 \mathrm{eV}$ between lone ion and ion pair systems for $\left[\mathrm{C}_{4} \mathrm{C}_{1} \mathrm{Im}\right]\left[\mathrm{C}(\mathrm{CN})_{3}\right]$.

By contrast, for calculated $\mathrm{N}$ 1s NEXAFS spectra, $\left[\mathrm{C}(\mathrm{CN})_{3}\right]^{-}$compared with the $\left[\mathrm{C}_{4} \mathrm{C}_{1} \mathrm{Im}\right]\left[\mathrm{C}(\mathrm{CN})_{3}\right]$ ion pair gave a difference in $E_{\mathrm{WL}}(\exp )$ of $<0.1 \mathrm{eV}$. Furthermore, excellent matches were obtained between experimental and calculated spectra of lone ions for the three ILs that contain a well-resolved peak from both the cation and the anion in a single NEXAFS spectrum (the $S$ 1s edge for $\left[S_{2,2,2}\right]\left[N T f_{2}\right]$ and the $N$ 1s edge for both $\left[\mathrm{C}_{4} \mathrm{C}_{1} \mathrm{Im}\right]\left[\mathrm{C}(\mathrm{CN})_{3}\right]$ and $\left.\left[\mathrm{C}_{4} \mathrm{C}_{1} \mathrm{Im}\right][\mathrm{SCN}]\right)$. These findings demonstrate that, for these three ILs at least, for calculated NEXAFS spectra the neighbouring ion solvation environment does not have a significant role.

The cause of this difference between ground state and excited state calculations is expected to be the fact that for NEXAFS spectra calculations, both the ground and excited states are in approximately the same solvation environment, i.e. NEXAFS spectra rely on, effectively, an internal reference, whereas VB spectra have an external reference (in the case of the calculations described above, the external reference is the vacuum level). One possible explanation is that in NEXAFS spectroscopy, ion-ion interactions (that is, the interactions responsible for the solvation environment in the liquid phase) have approximately the same effect on the initial (ground) and final (excited) states probed. Hence, the difference in energy between the final and initial states is unaffected by ion solvation.

\section{Conclusions}

TD-DFT with short-range corrected exchange-correlation functionals can be used to calculate accurate NEXAFS spectra for ILs, demonstrating that TD-DFT is an excellent method for investigating the excited state of ILs. Lone ions can be sufficient for calculating NEXAFS spectra, although in some cases calculations on ion pairs resulted in a much better match with experiment. In addition, some ion pair conformers led to spectra that varied significantly from experiment, indicating that these conformers do not capture the bulk liquid environment.

Considering these variations for some ILs, our recommendation is that ion pair calculations should be the minimum system size used for calculating NEXAFS spectra of ILs, as it cannot be predicted in advance whether lone ions and ion pairs will lead to similar calculated NEXAFS spectra. However, calculations using ion pair dimers did not lead to significant improvements relative to calculations using ion pairs, at least for the limited number of ILs investigated here. In addition, conformational effects can be very significant when calculating NEXAFS spectra. Certain ion pair conformers miss crucial cation-anion interactions that are present in the bulk liquid that other ion pair conformers do a better job of capturing. Therefore, we recommend that a rigorous conformational search may be necessary in order to be confident that the calculated NEXAFS spectra are appropriately capturing the bulk liquid phase for ILs. 
We found that the IL family previously used to test NEXAFS calculations, $\left[\mathrm{C}_{n} \mathrm{C}_{1} \mathrm{Im}\right]\left[\mathrm{NTf} \mathrm{f}_{2}\right]$, was not an ideal choice because the primary peak for both the cation and the anion in the $\mathrm{N}$ 1 spectra appear at approximately the same $h v$. A much better test-set of ILs, that give well-resolved peaks from both the cation and the anion, contains $\left[\mathrm{C}_{n} \mathrm{C}_{1} \operatorname{Im}\right]\left[\mathrm{C}(\mathrm{CN})_{3}\right]$, $\left[\mathrm{S}_{2,2,2}\right]\left[\mathrm{NTf}_{2}\right]$ and $\left[\mathrm{C}_{n} \mathrm{C}_{1} \mathrm{Im}\right][\mathrm{SCN}] \mathrm{ILs}$.

Our findings show that delocalised excited states exist for certain ILs, e.g. the ILs with a protic ammonium cation. These states are spread across multiple ions, i.e. the excited electron has a significant probability of being located on either the cation or anion, regardless of which ion contains the core-hole. This finding has significant implications for any process involving ILs or any IL property that involves the excited state, e.g. radiolysis and IL reduction, etc.

Whilst we have studied 12 ILs with a wide range of structural features, clearly there are outstanding questions to be answered. In particular, what factors determine whether an IL gives rise to delocalised excited states? More protic ILs should be studied using a combination of experimental and calculated NEXAFS spectra, as protic ILs have potential as relatively cheap yet effective ILs for lignocellulose processing. ${ }^{78}$ In addition, the conformer dependence of protic ammonium ILs has the potential to give insight into hydrogen bonding in the liquid phase. Protic ammonium cations are present in a wide range of applications, including those of great interest for biology ${ }^{79}$ and gas capture ${ }^{80}$.

Given the importance of the counterion to calculating the NEXAFS spectra, there is great potential to use NEXAFS spectroscopy to probe the interactions of IL ions with important solutes, e.g. water. In addition, NEXAFS spectroscopy has the potential to be used to monitor reactions in situ $^{43}$ in ILs; our results provide a valuable starting point for such studies.

\section{Acknowledgements}

KRJL acknowledges Imperial College London for the award of a Junior Research Fellowship and the Royal Society for the award of a University Research Fellowship. The authors are grateful to Jacek Osiecki and Karsten Handrup (MAX-lab, Sweden) for assistance with the experiments. The authors acknowledge the EPSRC for the award of a DTA studentship (RMF). MAX-lab are thanked for awarding beamtime on I311, and XMaS and the ESRF are thanked for awarding beamtime on BM28 (the XMaS beamline is a mid-range facility supported by the EPSRC). Diamond Light Source is also thanked for awarding beamtime on 109 (the data is presented in the ESI). This work was supported by the Physical Sciences Research Council [grant number EP/N002148/1 awarded to NAB].

\section{References}

1. D. R. MacFarlane, N. Tachikawa, M. Forsyth, J. M. Pringle, P. C. Howlett, G. D. Elliott, J. H. Davis, M. Watanabe, P. Simon and C. A. Angell, Energy Environ. Sci., 2014, 7, 232-250.

2. P. Hapiot and C. Lagrost, Chem. Rev., 2008, 108, 2238-2264.

3. X. Q. Sun, H. M. Luo and S. Dai, Chem. Rev., 2012, 112, 2100-2128.

4. A. Brandt, J. Gräsvik, J. P. Hallett and T. Welton, Green Chem., 2013, 15, 550-583.

5. K. R. J. Lovelock, Phys. Chem. Chem. Phys., 2012, 14, 5071-5089.

6. C. Lagrost, S. Gmouh, M. Vaultier and P. Hapiot, J. Phys. Chem. A, 2004, 108, 61756182.

7. X. Y. Zhu, P. Cui, D. J. Zhang and C. B. Liu, J. Phys. Chem. A, 2011, 115, 82558263.

8. Y. H. Yu, X. M. Lu, Q. Zhou, K. Dong, H. W. Yao and S. J. Zhang, Chem.-Eur. J., 2008, 14, 11174-11182.

9. S. P. Ong, O. Andreussi, Y. B. Wu, N. Marzari and G. Ceder, Chem. Mat., 2011, 23, 2979-2986. 
10. C. Liao, N. Shao, K. S. Han, X. G. Sun, D. E. Jiang, E. W. Hagaman and S. Dai, Phys. Chem. Chem. Phys., 2011, 13, 21503-21510.

11. P. Ballone and R. Cortes-Huerto, Faraday Discuss., 2012, 154, 373-389.

12. W. Buijs, G. J. Witkamp and M. C. Kroon, International Journal of Electrochemistry, 2012, 2012, 589050.

13. Y. H. Tian, G. S. Goff, W. H. Runde and E. R. Batista, J. Phys. Chem. B, 2012, 116, 11943-11952.

14. Y. Zhang, C. J. Shi, J. F. Brennecke and E. J. Maginn, J. Phys. Chem. B, 2014, 118, 6250-6255.

15. I. A. Shkrob and J. F. Wishart, J. Phys. Chem. B, 2009, 113, 5582-5592.

16. Z. P. Wang, L. Zhang, X. H. Chen, R. I. Cukier and Y. X. Bu, J. Phys. Chem. B, 2009, 113, 8222-8226.

17. Z. P. Wang, L. Zhang, R. I. Cukier and Y. X. Bu, Phys. Chem. Chem. Phys., 2010, 12, 1854-1861.

18. J. X. Liu, Z. P. Wang, M. Zhang, R. I. Cukier and Y. X. Bu, Phys. Rev. Lett., 2013, $110,6$.

19. C. J. Margulis, H. V. R. Annapureddy, P. M. De Biase, D. Coker, J. Kohanoff and M. G. Del Popolo, J. Am. Chem. Soc., 2011, 133, 20186-20193.

20. C. H. Xu, A. Durumeric, H. K. Kashyap, J. Kohanoff and C. J. Margulis, J. Am. Chem. Soc., 2013, 135, 17528-17536.

21. C. H. Xu and C. J. Margulis, J. Phys. Chem. B, 2015, 119, 532-542.

22. K. R. J. Lovelock, I. J. Villar-Garcia, F. Maier, H. P. Steinrück and P. Licence, Chem. Rev., 2010, 110, 5158-5190.

23. G. Hahner, Chem. Soc. Rev., 2006, 35, 1244-1255.

24. F. de Groot, Chem. Rev., 2001, 101, 1779-1808.

25. T. Fransson, Y. Harada, N. Kosugi, N. A. Besley, B. Winter, J. J. Rehr, L. G. M. Pettersson and A. Nilsson, Chem. Rev., 2016, 116, 7551-7569.

26. F. Jalilehvand, Chem. Soc. Rev., 2006, 35, 1256-1268.

27. S. Behyan, Y. F. Hu and S. G. Urquhart, J. Chem. Phys., 2013, 138, 214302.

28. R. Sarangi, P. Frank, K. O. Hodgson and B. Hedman, Inorg. Chim. Acta, 2008, 361, 956-964.

29. R. Sarangi, P. Frank, M. Benfatto, S. Morante, V. Minicozzi, B. Hedman and K. O. Hodgson, J. Chem. Phys., 2012, 137, 13.

30. R. Golnak, S. I. Bokarev, R. Seidel, J. Xiao, G. Grell, K. Atak, I. Unger, S. Thurmer, S. G. Aziz, O. Kuhn, B. Winter and E. F. Aziz, Sci Rep, 2016, 6, 8.

31. R. Golnak, J. Xiao, K. Atak, I. Unger, R. Seidel, B. Winter and E. F. Aziz, J. Phys. Chem. A, 2016, 120, 2808-2814.

32. S. Kuwabata, T. Tsuda and T. Torimoto, J. Phys. Chem. Lett., 2010, 1, 3177-3188.

33. T. Nishi, T. Iwahashi, H. Yamane, Y. Ouchi, K. Kanai and K. Seki, Chem. Phys. Lett., 2008, 455, 213-217.

34. K. Kanai, T. Nishi, T. Iwahashi, Y. Ouchi, K. Seki, Y. Harada and S. Shin, J. Chem. Phys., 2008, 129, 224507.

35. F. Rodrigues, G. M. do Nascimento and P. S. Santos, J. Electron Spectrosc. Relat. Phenom., 2007, 155, 148-154.

36. F. Rodrigues, G. M. do Nascimento and P. S. Santos, Macromol. Rapid Commun., 2007, 28, 666-669.

37. F. Rodrigues, D. Galante, G. M. do Nascimento and P. S. Santos, J. Phys. Chem. B, 2012, 116, 1491-1498.

38. C. Ehlert, M. Holzweber, A. Lippitz, W. E. S. Unger and P. Saalfrank, Phys. Chem. Chem. Phys., 2016, 18, 8654-8661.

39. Y. Horikawa, T. Tokushima, O. Takahashi, H. Hoke and T. Takamuku, J. Phys. Chem. B, 2016, 120, 7480-7487.

40. M. Wagstaffe, M. J. Jackman, K. L. Syres, A. Generalov and A. G. Thomas, ChemPhysChem, 2016, 17, 3430-3434. 
41. P. D'Angelo, A. Zitolo, V. Migliorati, E. Bodo, G. Aquilanti, J. L. Hazemann, D. Testemale, G. Mancini and R. Caminiti, J. Chem. Phys., 2011, 135, 7.

42. A. Zitolo, V. Migliorati, G. Aquilanti and P. D'Angelo, Chem. Phys. Lett., 2014, 591, 32-36.

43. P. B. J. Thompson, B. N. Nguyen, R. Nicholls, R. A. Bourne, J. B. Brazier, K. R. J. Lovelock, S. D. Brown, D. Wermeille, O. Bikondoa, C. A. Lucas, T. P. A. Hase and M. A. Newton, J. Synchrot. Radiat., 2015, 22, 1426-1439.

44. L. Triguero, L. G. M. Pettersson and H. Ågren, Phys. Rev. B, 1998, 58, 8097-8110.

45. N. A. Besley and F. A. Asmuruf, Phys. Chem. Chem. Phys., 2010, 12, 12024-12039.

46. N. A. Besley, M. J. G. Peach and D. J. Tozer, Phys. Chem. Chem. Phys., 2009, 11, 10350-10358.

47. R. M. Fogarty, K. R. J. Lovelock and P. A. Hunt, 2017, In preparation.

48. P. A. Hunt and I. R. Gould, J. Phys. Chem. A, 2006, 110, 2269-2282.

49. P. A. Hunt, B. Kirchner and T. Welton, Chem.-Eur. J., 2006, 12, 6762-6775.

50. P. A. Hunt, I. R. Gould and B. Kirchner, Aust. J. Chem., 2007, 60, 9-14.

51. R. M. Fogarty, R. P. Matthews, R. G. Palgrave, R. A. Bourne, K. Handrup, A. Brandt, T. Vander Hoogerstraete, P. A. Hunt and K. R. J. Lovelock, 2017, In preparation.

52. R. P. Matthews, C. Ashworth, T. Welton and P. A. Hunt, J. Phys.-Condes. Matter, 2014, 26, 14.

53. R. P. Matthews, T. Welton and P. A. Hunt, Phys. Chem. Chem. Phys., 2014, 16, 3238-3253.

54. R. P. Matthews, T. Welton and P. A. Hunt, Phys. Chem. Chem. Phys., 2015, 17, 14437-14453.

55. J. Rigby, S. B. Acevedo and E. I. Izgorodina, J. Chem. Theory Comput., 2015, 11, 3610-3616.

56. V. S. Bernales, A. V. Marenich, R. Contreras, C. J. Cramer and D. G. Truhlar, J. Phys. Chem. B, 2012, 116, 9122-9129.

57. G. F. De Gregorio, C. C. Weber, J. Grasvik, T. Welton, A. Brandt and J. P. Hallett, Green Chem., 2016, 18, 5456-5465.

58. T. Vander Hoogerstraete and K. Binnemans, Green Chem., 2014, 16, 1594-1606.

59. M. T. Clough, K. Geyer, P. A. Hunt, S. Son, U. Vagt and T. Welton, Green Chem., 2015, 17, 231-243.

60. I. J. Villar-Garcia, S. Fearn, G. F. De Gregorio, N. L. Ismail, F. J. V. Gschwend, A. J. S. McIntosh and K. R. J. Lovelock, Chemical Science, 2014, 5, 4404-4418.

61. A. W. Taylor, K. R. J. Lovelock, A. Deyko, P. Licence and R. G. Jones, Phys. Chem. Chem. Phys., 2010, 12, 1772-1783.

62. R. M. Fogarty, R. P. Matthews, C. R. Ashworth, T. Vander Hoogerstraete, R. A. Bourne, R. G. Palgrave, P. A. Hunt and K. R. J. Lovelock, 2017, In preparation.

63. R. M. Fogarty, R. Rowe, R. P. Matthews, M. T. Clough, C. R. Ashworth, A. Brandt, P. J. Corbett, R. G. Palgrave, E. F. Smith, R. A. Bourne, T. W. Chamberlain, P.

Thompson, P. A. Hunt and K. R. J. Lovelock, Faraday Discuss., 2017, DOI: 10.1039/C1037FD00155J.

64. A. D. Becke, Phys. Rev. A, 1988, 38, 3098-3100.

65. A. D. Becke, J. Chem. Phys., 1993, 98, 5648-5652.

66. C. T. Lee, W. T. Yang and R. G. Parr, Phys. Rev. B, 1988, 37, 785-789.

67. R. H. Hertwig and W. Koch, Chem. Phys. Lett., 1997, 268, 345-351.

68. M. J. Frisch, G. W. Trucks, H. B. Schlegel, G. E. Scuseria, M. A. Robb, J. R.

Cheeseman, G. Scalmani, V. Barone, B. Mennucci, G. A. Petersson, H. Nakatsuji, M. Caricato, X. Li, H. P. Hratchian, A. F. Izmaylov, J. Bloino, G. Zheng, J. L.

Sonnenberg, M. Hada, M. Ehara, K. Toyota, R. Fukuda, J. Hasegawa, M. Ishida, T. Nakajima, Y. Honda, O. Kitao, H. Nakai, T. Vreven, J. J. A. Montgomery, J. E.

Peralta, F. Ogliaro, M. Bearpark, J. J. Heyd, E. Brothers, K. N. Kudin, V. N.

Staroverov, R. Kobayashi, J. Normand, K. Raghavachari, A. Rendell, J. C. Burant, S. S. Iyengar, J. Tomasi, M. Cossi, N. Rega, J. M. Millam, M. Klene, J. E. Knox, J. B. Cross, V. Bakken, C. Adamo, J. Jaramillo, R. Gomperts, R. E. Stratmann, O. Yazyev, 
A. J. Austin, R. Cammi, C. Pomelli, J. W. Ochterski, R. L. Martin, K. Morokuma, V. G. Zakrzewski, G. A. Voth, P. Salvador, J. J. Dannenberg, S. Dapprich, A. D. Daniels, Ö. Farkas, J. B. Foresman, J. V. Ortiz, J. Cioslowski and D. J. Fox, Gaussian 09, Revision D.01, 2009.

69. S. Grimme, S. Ehrlich and L. Goerigk, J. Comput. Chem., 2011, 32, 1456-1465.

70. S. Hirata and M. Head-Gordon, Chem. Phys. Lett., 1999, 314, 291-299.

71. D. Robinson and N. A. Besley, Phys. Chem. Chem. Phys., 2010, 12, 9667-9676.

72. M. W. Buckley and N. A. Besley, Chem. Phys. Lett., 2011, 501, 540-546.

73. G. Capano, T. J. Penfold, N. A. Besley, C. J. Milne, M. Reinhard, H. Rittmann-Frank, P. Glatzel, R. Abela, U. Rothlisberger, M. Chergui and I. Tavernelli, Chem. Phys. Lett., 2013, 580, 179-184.

74. S. T. Skowron and N. A. Besley, Theor. Chem. Acc., 2012, 131, 8.

75. N. A. Besley, J. Chem. Theory Comput., 2016, 12, 5018-5025.

76. Y. H. Shao, Z. T. Gan, E. Epifanovsky, A. T. B. Gilbert, M. Wormit, J. Kussmann, A. W. Lange, A. Behn, J. Deng, X. T. Feng, D. Ghosh, M. Goldey, P. R. Horn, L. D. Jacobson, I. Kaliman, R. Z. Khaliullin, T. Kus, A. Landau, J. Liu, E. I. Proynov, Y. M. Rhee, R. M. Richard, M. A. Rohrdanz, R. P. Steele, E. J. Sundstrom, H. L. Woodcock, P. M. Zimmerman, D. Zuev, B. Albrecht, E. Alguire, B. Austin, G. J. O. Beran, Y. A. Bernard, E. Berquist, K. Brandhorst, K. B. Bravaya, S. T. Brown, D. Casanova, C. M. Chang, Y. Q. Chen, S. H. Chien, K. D. Closser, D. L. Crittenden, M. Diedenhofen, R. A. DiStasio, H. Do, A. D. Dutoi, R. G. Edgar, S. Fatehi, L. FustiMolnar, A. Ghysels, A. Golubeva-Zadorozhnaya, J. Gomes, M. W. D. Hanson-Heine, P. H. P. Harbach, A. W. Hauser, E. G. Hohenstein, Z. C. Holden, T. C. Jagau, H. J. Ji, B. Kaduk, K. Khistyaev, J. Kim, J. Kim, R. A. King, P. Klunzinger, D. Kosenkov, T. Kowalczyk, C. M. Krauter, K. U. Lao, A. D. Laurent, K. V. Lawler, S. V. Levchenko, C. Y. Lin, F. Liu, E. Livshits, R. C. Lochan, A. Luenser, P. Manohar, S. F. Manzer, S. P. Mao, N. Mardirossian, A. V. Marenich, S. A. Maurer, N. J. Mayhall, E. Neuscamman, C. M. Oana, R. Olivares-Amaya, D. P. O'Neill, J. A. Parkhill, T. M. Perrine, R.

Peverati, A. Prociuk, D. R. Rehn, E. Rosta, N. J. Russ, S. M. Sharada, S. Sharma, D. W. Small, A. Sodt, T. Stein, D. Stuck, Y. C. Su, A. J. W. Thom, T. Tsuchimochi, V. Vanovschi, L. Vogt, O. Vydrov, T. Wang, M. A. Watson, J. Wenzel, A. White, C. F. Williams, J. Yang, S. Yeganeh, S. R. Yost, Z. Q. You, I. Y. Zhang, X. Zhang, Y. Zhao, B. R. Brooks, G. K. L. Chan, D. M. Chipman, C. J. Cramer, W. A. Goddard, M. S. Gordon, W. J. Hehre, A. Klamt, H. F. Schaefer, M. W. Schmidt, C. D. Sherrill, D. G. Truhlar, A. Warshel, X. Xu, A. Aspuru-Guzik, R. Baer, A. T. Bell, N. A. Besley, J. D. Chai, A. Dreuw, B. D. Dunietz, T. R. Furlani, S. R. Gwaltney, C. P. Hsu, Y. S. Jung, J. Kong, D. S. Lambrecht, W. Z. Liang, C. Ochsenfeld, V. A. Rassolov, L. V. Slipchenko, J. E. Subotnik, T. Van Voorhis, J. M. Herbert, A. I. Krylov, P. M. W. Gill and M. Head-Gordon, Mol. Phys., 2015, 113, 184-215.

77. F. A. Asmuruf and N. A. Besley, Chem. Phys. Lett., 2008, 463, 267-271.

78. L. Chen, M. Sharifzadeh, N. Mac Dowell, T. Welton, N. Shah and J. P. Hallett, Green Chem., 2014, 16, 3098-3106.

79. B. M. Messer, C. D. Cappa, J. D. Smith, W. S. Drisdell, C. P. Schwartz, R. C. Cohen and R. J. Saykally, J. Phys. Chem. B, 2005, 109, 21640-21646.

80. W. S. Drisdell, R. Poloni, T. M. McDonald, T. A. Pascal, L. F. Wan, C. Das Pemmaraju, B. Vlaisavljevich, S. O. Odoh, J. B. Neaton, J. R. Long, D. Prendergast and J. B. Kortright, Phys. Chem. Chem. Phys., 2015, 17, 21448-21457. 